UNIVERSIDADE DE SÃO PAULO

INSTITUTO DE QUÍMICA

Programa de Pós-Graduação em CiênCias Biológicas (BIoquímica)

ÉRICA MoreIRA DE OLIVEIRA

PURIFICAÇÃo E CARACTERIZAÇÃo dE UMA CARBOXIPEPTIDASE E DE UMA DIPEPTIDASE DA LARVA DE TENEBRIO MOLITOR (COLEOPTERA)

São Paulo

$30 / 05 / 2008$ 
ÉRICA MOREIRA DE OLIVEIRA

\title{
PURIFICAÇÃo E CARACTERIZAÇÃo dE UMA CARBOXIPEPTIDASE E DE UMA DIPEPTIDASE DA LARVA DE TENEBRIO MOLITOR (COLEOPTERA)
}

\author{
Dissertação apresentada ao Instituto de \\ Química da Universidade de São Paulo para \\ obtenção do Título de Mestre em \\ Ciências na Área de Bioquímica
}

Orientador: Prof. Dr. Walter Ribeiro Terra

São Paulo

$30 / 05 / 2008$ 
ÉRICA MOREIRA DE OLIVEIRA

PURIFICAÇÃO E CARACTERIZAÇÃO DE UMA CARBOXIPEPTIDASE E DE UMA DIPEPTIDASE DA LARVA DE TENEBRIO MOLITOR (COLEOPTERA)

Dissertação apresentada ao Instituto de Química da Universidade de São Paulo para obtenção do Título de Mestre em Ciências na Área de Bioquímica

Aprovado em:

\section{Banca Examinadora}

Prof. Dr.

Instituição:

Assinatura:

Prof. Dr.

Instituição:

Assinatura:

\section{Orientador:}

Prof. Dr. Walter Ribeiro Terra 
Dedico este trabalho a meus pais João Batista e Maria da Glória, a meus irmãos Isaac e Maria Aparecida, a minha sobrinha Natally e a minha amiga Thaís Bifano. A vocês com todo meu amor e carinho, minha gratidão eterna. 


\section{AgRADECIMENTOS}

Agradeço a todas as pessoas e instituições que de alguma forma contribuíram para a realização deste trabalho, em especial:

Ao meu orientador Walter Ribeiro Terra, por ter me acolhido em seu laboratório e ter permitido a realização deste trabalho.

À profa. Dra. Clélia Ferreira também pelo acolhimento e discussões.

À Thaís Bifano pelo extremo incentivo e enorme ajuda emocional e profissional, sempre me fazendo lutar pelos meus objetivos.

Ao Dr. Fernando Ariel Genta e a Dra. Adriana Lopes pela ajuda na confecção de protocolos e análise de resultados.

A toda minha família por todo apoio, paciência e compreensão.

A todos os amigos do laboratório de Bioquímica de insetos, Thaís, Dra. Anna, Dra. Maria Cícera, Dr. Fernando, Alexandra, Lucas, Fábio, Ivan, Daniela, Nathália, Marcelo, André, Thiago e Augusto, pela ajuda, carinho e amizade.

Aos amigos Venezuelanos, que tiveram que partir, Anna, John Mantilla e ao filho deles Daniel, por terem me acolhido muitas vezes para jantares, pizzas, festas, sempre proporcionando ótimos momentos de descontração. Saudade sempre de vocês.

Aos amigos Érika Kague e Maurício Watanabe e aos amigos do departamento de Bioquímica, Patrícia Pessoa, Fernando Shoenmaker, 
Fernanda, Fabiana Cançado, Laila e Daniela Gonzáles pelo apoio, amizade e incentivo.

Às técnicas e amigas Luiza Nakabayashi, Maria Ivanilde Marcelino e Cristiane Cardoso por todo o auxílio durante os anos de mestrado.

Ao CNPq pela bolsa concedida.

Durante a realização deste trabalho, o laboratório foi mantido por auxílios concedidos pelo CNPq e FAPESP. 


\section{RESUMO}

Oliveira, E. M., Purificação e caracterização de uma carboxipeptidase e de uma dipeptidase da larva de Tenebrio molitor (Coleoptera). Ano: 2008. 47 páginas. Dissertação de Mestrado. Programa de Pós-Graduação em Bioquímica. Instituto de Química, Universidade de São Paulo, São Paulo.

Devido aos problemas, ambientais e à população humana, causados pelos inseticidas químicos, novas investigações para o controle de insetos tornaram-se necessárias. Para isto, um maior conhecimento sobre a fisiologia digestiva dos insetos torna-se essencial, visto que o intestino é uma interface, grande e relativamente desprotegida, entre o inseto e o seu ambiente. Neste contexto, nosso trabalho envolve a purificação e caracterização de uma dipeptidase e de uma carboxipeptidase digestivas de T. molitor. Estas enzimas, compreendem as classes de enzimas digestivas de insetos menos estudadas. $\mathrm{O}$ estudo de distribuição das atividades de dipeptidase e carboxipeptidase nas diferentes regiões do intestino médio de larvas de $T$. molitor mostrou que essas enzimas encontram-se majoritariamente no conteúdo luminal. Para a purificação da dipeptidase e carboxipeptidase foram utilizadas cromatografias de troca iônica e filtração em gel. A carboxipeptidase purificada era muito instável para estudos mais detalhados. O estudo dos parâmetros cinéticos mostrou que a dipeptidase digestiva de T. molitor possui massa molecular de $38,6 \mathrm{kDa}, \mathrm{pH}$ ótimo 7,4 , baixa solubilidade a fenantrolina e parece preferir dipeptídeos com cadeia lateral volumosa na posição P1. Devido a essas propriedades, mesmo sendo solúvel, assemelha-se a dipeptidase de membrana (EC 3.4.13.19).

Palavras-chave: Tenebrio molitor, carboxipeptidase, dipeptidase, caracterização cinética, digestão terminal. 


\section{ABSTRACT}

Oliveira, E. M., Purification and characterization of a carboxypeptidase and a dipeptidase from Tenebrio molitor (Coleoptera) larvae. Ano: 2008. 47 páginas. Master Thesis. Program in Biochemistry. Instituto de Química, Universidade de São Paulo, São Paulo.

Because of adverse effects caused by insecticides in environment and in animals and humans, new methods for insect control are necessary. Knowledge on insect digestive physiology may be instrumental in this direction, as the gut is the major interface between insect and its environment. Our work involves the purification and characterization of a digestive carboxypeptidase and a digestive dipeptidase from Tenebrio molitor. Those enzymes comprise the class of insect digestive enzymes less studied. Distribution studies showed that $T$. molitor dipeptidase and carboxypeptidase are more active in the midgut content. The purification of $T$. molitor dipeptidase and carboxypeptidase was attained using a combination of anion-exchange chromatographies and gel filtration. The optimum $\mathrm{pH}$ of dipeptidase is 7.6 and the carboxypeptidase is 7.4. The kinetic parameters showed that the T. molitor digestive dipeptidase prefers as substrates dipeptides having a large lateral chain in $\mathrm{P} 1$ position.

Keywords: Tenebrio molitor, carboxypeptidase, dipeptidase, kinetic characterization, terminal digestion. 


\section{Abreviaturas}

$\begin{array}{ll}\text { Ala-Gly } & \text { Alanil-L-Glicina } \\ \text { Gly-Leu } & \text { Glicil-L-Leucina } \\ \text { Gly-Pro } & \text { Glicil-L-Prolina } \\ \text { kDa } & \text { Quilodaltons } \\ \text { LpNA } & \text { Leucina p-nitroanilida } \\ \text { p/v } & \text { Peso/volume } \\ \text { Pro-Gly } & \text { Prolil-L-Glicina } \\ \text { PM } & \text { Peso molecular } \\ \text { pNa } & \text { p-nitroanilina } \\ \text { SDS } & \text { Dodecil sulfato de sódio } \\ \text { PAGE } & \text { Eletroforese em gel de poliacrilamida } \\ \text { Tris } & \text { Tris (hidroximetil)-amino metano } \\ \text { V } & \text { Volts } \\ \text { ZGly-Phe } & \text { N- carbobenzoxi Glicil L-Fenilalanina }\end{array}$


ÍNDICE

1 - INTRODUÇÃO .......................................................................................... 1

1.1 - CONSIDERAÇÕES INICIAIS ..................................................................... 1

$1.2-$ Estrutura do TUBO DIGESTIVo DOS INSETOS 3 ..................................

1.3 - DigeSTÃo DE PROTEÍNAS ................................................................... 5

1.4 - CARBOXIPEPTIDASES DIGESTIVAS DE INSETOS ............................... 6

1.5 - DIPEPTIDASES DIGESTIVAS DE INSETOS ........................................ 10

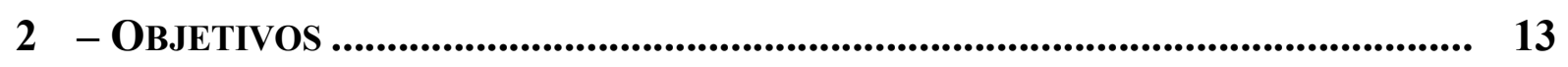

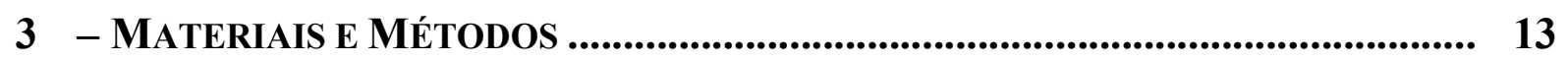

3.1 - ANIMAIS ............................................................................................... 13

3.2 - PREPaRaÇão doS ANIMAIS disSeCAdos ......................................... 14

3.3 - DETERMINAÇÃO DE PROTEÍNA …........................................................ 15

3.4 - DETERMINAÇÃO DAS ATIVIDADES ENZIMÁTICAS .............................. 15

3.5 - CromatogRafiaS ........................................................................... 16

3.5.1 - Cromatografia Para dessalinizaÇão de AMOSTRA EM COLUNA HITRAP DESALTING ................................................. 16

$\begin{array}{lllllll}\text { 3.5.2 - } & - & \text { CROMATOGRAFIA DE } & \text { TROCA } & \text { IÔNICA } 16\end{array}$

3.5.3 - CROMATOGRAFIA DE GEL FILTRAÇ̃̃o .................................. 17

3.6 - ELETROFORESE EM GEL DE POLIACRILAMIDA EM CONDIÇÕES 
DESNATURANTES

3.7 - DIÁLISE

3.8 - DETERMINAÇÃo DO EFEITO DO PH SOBRE A ATIVIDADE DAS DIPEPTIDASE E CARBOXIPEPTIDASE

3.9 - DETERMINAÇÃO DO $K_{M}$ E DA $V_{\text {MAX }}$ DA DIPEPTIDASE

3.10 - ENSAIO DE INIBIÇÃO ENZIMÁTICA

4.1 - DistribuiçÃo DA ATIVIDAdE DE DIPEPTIDASE E CARBOXIPEPTIDASE NAS DIFERENTES REGIÕES DO INTESTINO MÉDIO DE T. MOLITOR

4.2 - PURIFICAÇÃo DA DIPEPTIDASE E DA CARBOXIPEPTIDASE PRESENTES NO CONTEÚDO LUMINAL DO INTESTINO MÉDIO DAS LARVAS DE T. MOLITOR

4.3 - EFEITO DO PH SOBRE A ATIVIDADE DA DIPEPTIDASE E CARBOXIPEPTIDASE

4.4 - PROPRIEDADES CINÉTICAS DA DIPEPTIDASE PURIFICADA

5.1 - PURIFICAÇÃo DA DIPEPTIDASE E DA CARBoXIPEPTIDASE PRESENTES NO CONTEÚDO LUMINAL DO INTESTINO MÉDIO DAS LARVAS DE T. MOLITOR .

5.2 - PROPRIEDAdeS CINÉTICAS DA CARbOXIPEPTIDASE E 
DIPEPTIDASES INTESTINAIS DE $T$. MOLITOR

5.3 - ORGANIZAÇÃo DA DIGESTÃo FINAL DE PROTEÍNAS

6 - CONCLUSÕES

7 - BIBLIOGRAFIA

\section{ÍNDICE DE FIGURAS E TABELAS}

Figura 1 - Esquema geral do tubo digestivo dos insetos. Copiado de Terra e Ferreira, (1994)

Figura 2 - Perfil cromatográfico para aminopeptidase, dipeptidase e carboxipeptidase em coluna HiTrap Q

Figura 3 - Perfil cromatográfico para aminopeptidase, dipeptidase e carboxipeptidase em coluna Resource Q

Figura 4 - Perfil cromatográfico para dipeptidase e carboxipeptidase em Resource Q

Figura 5 - Perfil cromatográfico para dipeptidase e carboxipeptidase em coluna Superdex 75

Figura 6 - SDS-PAGE em gel 12\% das frações 16 a 24 do eluido da coluna Superdex 75 (figura 4)

Figura 7 - Efeito do pH sobre a taxa de hidrólise de Gly-Leu (A) e ZGly-Phe (B)

Figura 8 - Inibição por 1,10-fenantrolina da hidrólise de Gly-Leu pela dipeptidase purificada de intestino da larva de $T$. molitor.

Tabela 1 - Distribuição da atividade de dipeptidase e carboxipeptidase nas diferentes regiões do intestino médio de T. molitor

Tabela 2 - Rendimento dos passos da marcha de purificação da dipeptidase e 
carboxipeptidase de T. molitor

Tabela 3 - Determinação da eficiência catalítica da dipeptidase purificada de $T$. molitor, sobre cinco substratos diferentes

\section{1 - INTRODUÇÃO}

\section{1 - CONSIDERAÇÕES INICIAIS}

Embora o estudo sobre a digestão em insetos tenha começado a mais de um século, nosso entendimento sobre tal assunto está longe de ser completado. Com o surgimento e a utilização de inseticidas químicos na década de 40, o que resultou em uma crença inicial de que se havia chegado a uma solução definitiva para o problema das pragas agrícolas, o estudo sobre a digestão em inseto passou por um período de lentidão (Terra e Ferreira, 2005).

Devido aos problemas, ambientais e à população humana, causados pelos inseticidas químicos, novas investigações para o controle de insetos tornaram-se necessárias. Ao longo do tempo, diversas abordagens para o controle de pragas como o controle biológico (o qual faz uso de inimigos naturais dos insetos praga, para o controle destes) ou a utilização de plantas transgênicas (teoricamente menos danosas ao meio ambiente que os inseticidas) foram colocadas à disposição dos sistemas agrícolas. Contudo, a necessidade de investimentos nesta área tornou-se evidente com a verificação da existência de diferentes tipos de resistências tanto aos controles biológicos como aos inseticidas e as plantas transgênicas (Hilder e Boulter, 1999; Bobrowski et al., 2003), reforçando a idéia de que técnicas diversificadas de ataque às 
pragas devem ser utilizadas. O consenso atual prega a utilização da maior variedade possível de formas de controle, evitando uma pressão seletiva específica exagerada (McGaughey e Whalon, 1992).

Um maior conhecimento sobre a fisiologia digestiva dos insetos tornou-se, então, essencial para o desenvolvimento de novos métodos de controle de insetos praga, visto que o intestino é uma interface, grande e relativamente desprotegida, entre o inseto e o seu ambiente (Terra e Ferreira, 2005). Tal conhecimento inclui os estudos sobre os compartimentos intestinais onde as diferentes fases da digestão ocorrem e as propriedades das enzimas participantes.

A determinação da distribuição das enzimas nos vários compartimentos do canal alimentar permite esclarecer os passos pelos quais o alimento é hidrolisado nos diferentes sítios e auxilia na compreensão da atuação fisiológica de uma enzima.

O estudo das propriedades das enzimas digestivas permite-nos conhecer, por exemplo, em que região do tubo digestivo essas enzimas atuam e qual seu papel fisiológico, pois podemos determinar quais são seus substratos naturais, e se ela é responsável pela hidrólise de um composto ou de vários compostos relacionados entre si.

A fim de contribuir para o maior número de dados possíveis sobre a digestão em insetos, Terra $(1988,1990)$ propôs que o estudo fosse realizado a partir de insetos representativos que permitiriam estabelecer hipóteses sobre a organização da digestão em insetos. A ordem Coleoptera é a maior ordem dentre os insetos, sendo que os besouros constituem cerca de $40 \%$ dos insetos e $30 \%$ dos animais (Richards e Davis, 
1977). Tendo em vista esses aspectos, este trabalho contemplará o estudo de uma dipeptidase e de uma carboxipeptidase envolvidas na digestão de proteínas em $T$. molitor, uma importante praga cosmopolita de alimentos estocados. Esse inseto tem sido o objeto de numerosos estudos sobre fisiologia digestiva, constituindo assim, um bom modelo para o estudo de digestão em Coleoptera. pH luminal, localização das peptidases no intestino médio e algumas das propriedades destas enzimas digestivas foram estudados por Terra et al.; Terra et al.; Ferreira et al., (1990); Levinsky et al., (1977). Porém, existem numerosas questões ainda a serem resolvidas a respeito da fisiologia e bioquímica da digestão nesse inseto.

\section{2 - ESTRUTURA DO TUBO DIGESTIVO DOS INSETOS}

Um diagrama generalizado do intestino de insetos é apresentado na figura 1 (Chapman, 1985).

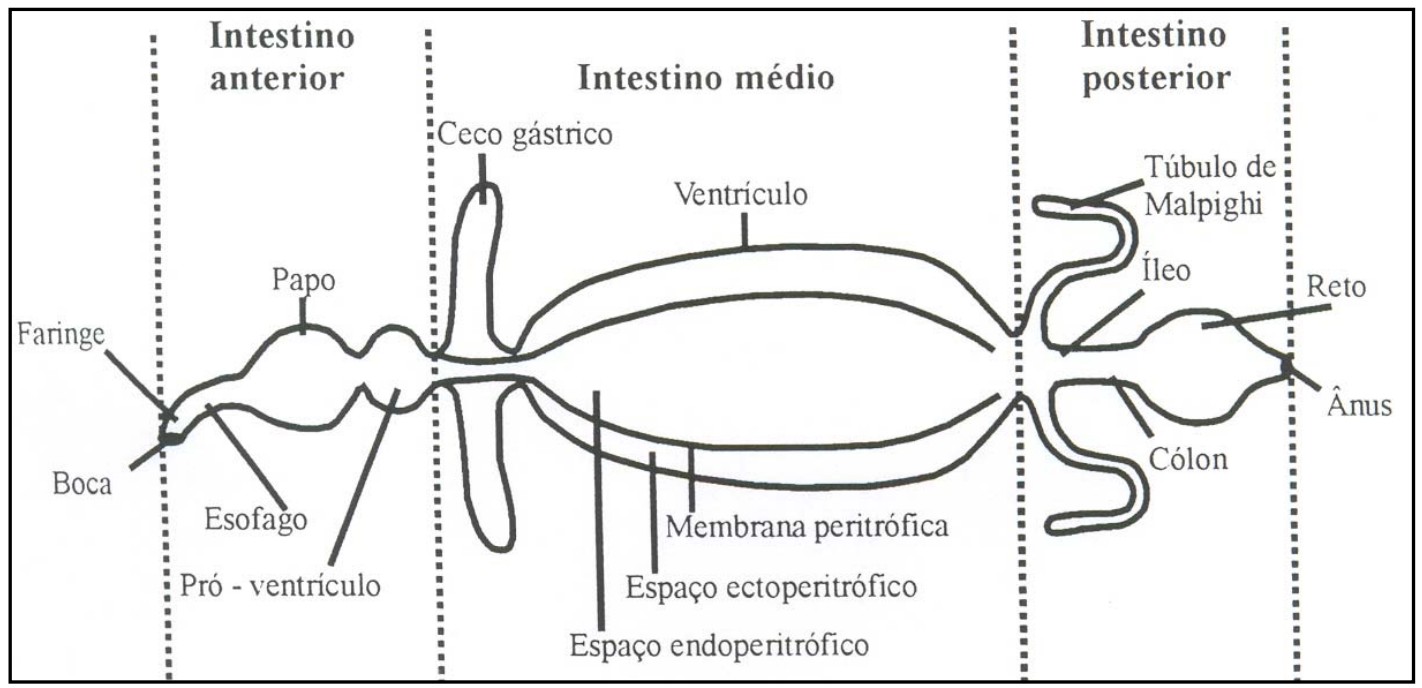


Figura 1 - Esquema geral do tubo digestivo dos insetos. Copiado de Terra e Ferreira, (1994).

O intestino anterior começa na boca, inclui a cavidade bucal (dentro da qual as glândulas salivares despejam suas secreções), a faringe, o esôfago, o papo e o próventrículo. O papo é um órgão de armazenamento para muitos insetos e para outros serve também como um sítio para digestão. No entanto, as enzimas encontradas no papo são originadas do refluxo de enzimas secretadas pelo intestino médio. $\mathrm{O}$ intestino anterior é envolto por uma cutícula e em alguns insetos é reduzido a um pequeno tubo. Em alguns insetos, o pró-ventrículo representa um órgão triturador. Porém, na maioria das espécies ele desempenha a função de uma válvula controlando a entrada de alimento no intestino médio, o principal sítio de digestão e absorção dos nutrientes.

O intestino médio consiste de um tubo simples (ventrículo) do qual podem partir extensões em forma de sacos com fundo cego, encontrado normalmente no início do intestino médio, denominado cecos gástricos. Na maioria dos insetos, o intestino médio é coberto por uma membrana, quitino-protéica, denominada membrana peritrófica, a qual separa o conteúdo luminal em dois compartimentos: o espaço endoperitrófico (dentro da membrana) e o espaço ectoperitrófico (entre a membrana e o epitélio do intestino médio). Na região do piloro, o esfíncter que separa o intestino médio do intestino posterior, estão os túbulos de Malpighi que são os órgãos responsáveis pela excreção nesses animais.

O intestino posterior está envolvido na absorção de água e íons e termina no ânus. 


\section{3 - Digestão de Proteínas}

A digestão inicial de proteínas é caracterizada pela hidrólise do substrato protéico ingerido a oligopeptídeos de tamanho menor. Esta fase da digestão é realizada por proteinases (endopeptidases), que são enzimas que clivam ligações peptídicas internas das proteínas. Essas endopeptidases estão divididas em cinco classes de acordo com os grupos envolvidos em catálise (serina, cisteína, aspártico, metalo e treonina proteinases) e apresentam diferentes especificidades. Desta forma, diferentes proteinases são necessárias para digestão de proteínas para que haja hidrólise das ligações peptídicas formadas pelos diferentes resíduos de aminoácidos ap longo da cadeia peptídica.

Os oligopeptídeos resultantes da ação das proteinases são atacados pelas exopeptidases, caracterizando a digestão intermediária. As exopeptidases removem aminoácidos a partir da porção N-terminal (aminopeptidase) e da porção C-terminal (carboxipeptidase) de peptídeos, sendo que estas duas classes de enzimas liberam um resíduo de aminoácido em cada passo catalítico. Finalmente, os dipeptídeos gerados são hidrolisados pelas dipeptidases. As diferentes fases da digestão de proteínas são igualmente importantes dado que apenas aminoácidos livres são absorvidos pelas células intestinais.

No entanto, o estudo sobre digestão de proteínas em insetos tem se concentrado no estudo de proteinases e aminopeptidases (Terra e Ferreira, 2004), incluindo a 
purificação e caracterização da tripsina (serina proteinases) (Cristofoletti et al., 2001) e da catepsina-L de T. molitor (cisteína-proteinase) (Cristofoletti et al., 2005) que são as enzimas envolvidas na digestão inicial no inseto modelo deste projeto e também da aminopeptidase de T. molitor (Cristofoletti e Terra, 1999). Entretanto, existem poucos estudos a respeito das carboxipeptidases e, principalmente, sobre as dipeptidases de insetos.

\section{4 - CARBOXIPEPTIDASES DIGESTIVAS DE INSETOS}

Carboxipeptidases são exopeptidases que catalisam a hidrólise de ligações peptídicas a partir da região C-terminal de peptídeos e proteínas. Esta ação enzimática pode ser realizada por enzimas de dois diferentes mecanismos catalíticos: metalocarboxipeptidases, as quais possuem um átomo de $\mathrm{Zn}^{2+}$ diretamente envolvido em catálise e as serino-carboxipeptidases, as quais contém um resíduo de serina no sítio ativo pertencente à tríade Ser/His/Asp característica das serino proteinases (Avilés et al., 1993).

Entre as metalo-carboxipeptidases, o grupo de enzimas melhor estudado é o da família M14 segundo a classificação de Barrett e colaboradores (2004). As carboxipeptidases pertencentes à família M14 podem ser classificadas com base na sua especificidade pelo substrato (Vendrell et al., 2000). Neste contexto, duas formas de carboxipeptidases digestivas têm sido propostas em insetos em analogia às enzimas de mamíferos: carboxipeptidase A, que tem preferência por resíduos C-terminais 
hidrofóbicos (posição P1'), alifáticos (A1) e aromáticos (A2) e carboxipeptidase B, que é específica para resíduos básicos como Lys e Arg C-terminais (posição P1') (Bown et al., 1998; Gardell et al., 1988).

Dependendo do critério usado, as carboxipeptidases podem ser classificadas de diferentes maneiras. Uma das subdivisões é baseada no envolvimento das enzimas em processos fisiológicos específicos e classifica estas enzimas em digestivas que inclui as carboxipeptidases pancreáticas A1, A2 e B as quais possuem funções, tipicamente digestivas. E regulatórias, onde estão as outras carboxipeptidases de mamíferos que agem em vários processos fisiológicos, principalmente em tecidos e fluidos nãodigestivos. (Vendrell et al., 2000). As carboxipeptidases regulatórias e pancreáticas exibem similaridades entre os sítios ativos, sendo o domínio de ligação a zinco do tipo HXXE...H, onde os três ligantes de zinco são uma histidina, um glutamato localizado dois resíduos depois e uma segunda histidina localizada 108 - 135 resíduos de aminoácidos depois da primeira histidina a partir do C-terminal.

A partir de estudos cristalográficos, é possível identificar os resíduos envolvidos em ligação ao substrato e na catálise: Asn-144, Arg-145, Tyr-248 em S1'; Arg-127 e Glu-270 em S1; Arg-71, Ser-197, Tyr-198 e Ser-199 em S2; Phe-279 em S3 e Glu-122, Arg-124 e Lys-128 em S4. A carboxila terminal do substrato peptídico interage com os resíduos de aminoácidos que constituem o S1' (Asn-144, Arg-145 e Tyr-248), enquanto a carbonila da ligação peptídica a ser hidrolisada é posicionada perto do Glu-270, Arg-270 e do íon zinco. Todos estes resíduos são conservados entre as carboxipeptidases digestivas e muitos deles entre as carboxipeptidases regulatórias, 
as diferenças mais importantes estão restritas aos aminoácidos que definem a especificidade pelo substrato ou aos aminoácidos localizados nas regiões superficiais (Vendrell et al., 2000).

Enzimas digestivas similares a carboxipeptidase A são comuns em insetos e a maioria tem $\mathrm{pH}$ ótimo entre 7,5 - 9,0 e pesos moleculares entre $20-50 \mathrm{kDa}$ (Terra e Ferreira, 1994). As carboxipeptidases A digestivas foram clonadas e seqüenciadas a partir dos Diptera Similium vitatum (Ramos et al., 1993); Anopheles gambiae (Edwards et al., 1997) e Aedes aegypti (Edwards et al., 2000) e dos Lepidoptera Helicoverpa armigera (Bown et al., 1998) e Trichoplusia ni (Wang et al., 2004). Em T. ni a atividade de carboxipeptidase $\mathrm{B}$ também foi medida, porém, a atividade de carboxipeptidase A mostrou-se majoritária sendo oito vezes maior, exibindo ambas atividade máxima em pH 8,0 - 8,5 (Wang et al., 2004). A enzima da mariposa $H$. armigera foi expressa (Bown et al., 1998) e submetida a estudos cristalográficos (Estébanez-Perpiñá et al. 2001). As seqüências possuem peptídeo sinal e de ativação e características típicas de carboxipeptidases A, incluindo os resíduos His 69, Glu 72 e His 196, que ligam o íon zinco catalítico, e Arg 71, Asn 144, Arg 145 e Tyr 248, responsáveis pela ligação ao substrato e Arg 127 e Glu 270 para catálise. A despeito da semelhança geral da procarboxipeptidase de $H$. armigera com a procarboxipeptidase A humana, há diferenças nas alças entre as estruturas secundárias conservadas, incluindo a alça onde o processo de ativação ocorre. Outra diferença importante é o resíduo 255 (fundo da bolsa $\mathrm{Sl}^{\prime}$ ) que define a especificidade da enzima. Nas seqüências das enzimas de mamíferos, são encontrados resíduos de Ile e Asp nas carboxipeptidases A 
e B, respectivamente. No entanto, na carboxipeptidase A de $H$. armigera é verificado um resíduo de serina nesta posição. Esta substituição leva a um aumento no tamanho do subsítio S1' influenciando a especificidade da enzima (Estebánez-Perpinã et al., 2001)

Uma carboxipeptidase digestiva presente no inseto $H$. armigera foi caracterizada e mostrou nova especificidade (Bown e Gatehouse, 2004). O cDNA HaCA42 do intestino da larva deste inseto codifica uma carboxipeptidase na qual a seqüência é similar às enzimas pertencentes a família M14, mas com uma especificidade para resíduos ácidos C-terminais. Essa carboxipeptidase hidrolisa substratos sintéticos para glutamato carboxipeptidases (FAEE, furilacriloil-Glu-Glu com Glu C-terminal), mas não hidrolisa substratos sintéticos para carboxipeptidases A e B (FAPP, furilacriloilPhe-Phe ou FAAK, furilacriloil-Ala-Lys com Phe e Lys C-terminais respectivamente). A enzima mostrou ser altamente específica para glutamato C-terminal em substratos peptídicos sendo que foi observada pouca hidrólise de substratos contendo aspartato C-terminal.

As diferenças comentadas entre as carboxipeptidase A de insetos e de mamíferos levam as previsões de diferenças no comportamento cinético frente a inibidores. Entretanto, não existem estudos desse tipo, nem dados detalhados de nenhuma espécie com carboxipeptidase A de Coleoptera.

Enzimas semelhantes a carboxipeptidases B foram detectadas em intestinos de insetos (Terra e Ferreira, 1994), mas estas são menos ativas do que as 
carboxipeptidases A. A despeito disso, uma carboxipeptidase B foi clonada e seqüenciada a partir da mariposa T. ni (Wang et al., 2004).

\section{5 - DIPEPTIDASES DIGESTIVAS DE INSETOS}

Dipeptidases hidrolisam dipeptídeos e são classificadas de acordo com a especificidade pelos seus substratos. Essas enzimas são, principalmente, conhecidas em vertebrados. Nesses animais as dipeptidases são, usualmente, descritas como: carnosinases, as quais agem sobre dipeptídeos do tipo aminoacil-L-histidina; prolil dipeptidases, que hidrolisam dipeptídeos do tipo Pro-X; prolina dipeptidases, ativa contra dipeptídeos X-Pro e dipeptidases hidrolases, as quais possuem uma variedade de especificidade, embora clivando, preferencialmente, dipeptídeos hidrofóbicos (Nomenclature Committee, 1992).

As dipeptidases compreendem as peptídeo-hidrolases menos conhecidas de insetos. Existem poucos trabalhos nos quais ensaios para dipeptidases foram realizados e pouca atenção tem sido dada à caracterização dessas enzimas.

Atividade para dipeptidase contra Ala-Gly foi detectada no conteúdo luminal e nas células intestinais de Locusta migratoria (Orthoptera: Acrididae) e Dysdercus fasciatus (Hemiptera: Pyrrhocoridae) (Khan, 1962). Ferreira e Terra (1989) observaram atividade sobre Gly-Leu no intestino médio de Pheropsophus aequinoctialis (Coleoptera: Carabidae), cerca de $40 \%$ da atividade foi encontrada na forma solúvel e $60 \%$ como uma enzima ligada à membrana. Homogeneizados de intestino médio de Drosophila melanogaster (Diptera: Drosophilidae) mostraram 
atividade contra Leu-Pro e Phe-Leu (Hall, 1988). Embora os resultados sugiram a ocorrência de dipeptidases nessas espécies, é possível que parte da atividade observada resulte de uma aminopeptidase residual.

A ocorrência de uma dipeptidase verdadeira foi mostrada, a partir de dados cromatográficos, no intestino médio de Rhodnius prolixus (Hemiptera: Reduviidae), embora a especificidade pelo substrato não tenha sido estudada (Garcia e Guimarães, 1979). A demonstração de uma dipeptidase verdadeira como uma enzima distinta de aminopeptidase foi seguida por estudos em outros insetos. Usando Gly-Leu como substrato, uma dipeptidase foi encontrada no intestino médio de larvas de Musca domestica presente somente nas membranas microvilares das células e tem $\mathrm{pH}$ ótimo 8,0, um peso molecular de $111 \mathrm{kDa}$ e Km de 3,7 mM (Jordão e Terra, 1989). As larvas de Spodoptera frugiperda (Lepidoptera: Noctuidae) possuem duas dipeptidases (ensaiadas com Gly-Leu) restritas às células do intestino médio. Uma delas é solúvel e associada ao glicocálix, possui $\mathrm{pH}$ ótimo 8,0 e peso molecular de $95 \mathrm{kDa}$, a outra é ligada a membrana e possui $\mathrm{pH}$ ótimo 8,2 e peso molecular $130 \mathrm{kDa}$ (Ferreira et al., 1994).

As dipeptidases melhor estudadas até o momento foram as encontradas no tubo digestivo das larvas de Rhynchosciara americana (Diptera). Essas enzimas são encontradas, principalmente, nos cecos gástricos, onde se dá a maior parte da digestão terminal nesse inseto (Klinkowstrom et al., 1995). A atividade de dipeptidase (substrato Gly-Leu) nos cecos é parcialmente solúvel e parcialmente ligada à membrana. A atividade solúvel é resolvida por filtração em gel em duas enzimas (peso 
molecular 63 e $73 \mathrm{kDa}$ ) que hidrolisam tanto Gly-Leu quanto Pro-Gly, porém com eficiências diferentes. As duas enzimas também diferem quanto a sua estabilidade na presença de EDTA e no grau de inibição por 1,10-fenantrolina e por hidroxamatos de aminoácidos. A dipeptidase ligada à membrana foi solubilizada por Triton X-100 e por papaína. Cromatografia em coluna de filtração em gel sugere que há uma forma de enzima com um peso molecular de $86 \mathrm{kDa}$. Nenhuma atividade sobre Gly-Pro foi detectada no tubo digestivo de $R$. americana. Já a atividade sobre carnosinase ( $\beta$ alanil-histidina) foi encontrada tanto na fração solúvel quanto ligada à membrana e é independente daquelas que hidrolisam Gly-Leu e Pro-Gly. As dipeptidases de $R$. americana que são capazes de clivar Gly-Leu e Pro-Gly são semelhantes a dipeptidase de mamíferos (EC 3.4.13.18), embora, em contraste com essa, elas são muito ativas sobre Pro-Gly (Klinkowstrom et al., 1995). Em mamíferos, dipeptídeos do tipo Pro-X são hidrolisados principalmente por outra enzima, a prolil dipeptidase, que em vários tecidos de mamíferos é idêntica a carnosinase. Os resultados obtidos para $R$. americana indicam que suas dipeptidases apresentam uma especificidade mais ampla que as de mamíferos, de modo análogo ao que ocorre com as aminopeptidases (Cristofoletti e Terra, 1999).

Uma prolil dipeptidase humana foi purificada e caracterizada a partir da expressão desta proteína em células de insetos infectados por baculovírus. Estudos cinéticos mostraram que a enzima recombinante tem valores de $\mathrm{k}_{\mathrm{cat}}$ similares às outras prolil dipeptidases, quando ensaiadas com H-Gly-Pro-pNA. A prolil dipeptidase humana mostrou possuir especificidade por diferentes substratos, sendo os melhores: 
H-Ala-Pro-pNA e H-Gly-Pro-pNA, os quais possuem aminoácidos de cadeia lateral curta (Ala e Gly) na posição P2 e Pro na posição P1 (Chen et al., 2004).

\section{4 - OBJETIVOS}

Esse projeto tem por objetivo verificar a localização de uma carboxipeptidase e de uma dipeptidase digestivas presentes em T. molitor (Coleoptera). As enzimas mais abundantes serão isoladas, purificadas e os seus parâmetros cinéticos serão determinados.

3 - MATERIAis E MÉtodos

\section{1 - ANIMAIS}

Culturas estoque de T. molitor (Coleoptera: Tenebrionidae) foram mantidas em farelo de trigo à temperatura de $24-26^{\circ} \mathrm{C}$ e uma umidade relativa de $70-75 \%$. Larvas completamente desenvolvidas (cada uma pesando cerca de $0,12 \mathrm{~g}$ ) de ambos os sexos foram utilizadas nas preparações. 


\section{2 - PREPARAÇÃO DOS ANIMAIS DISSECADOS}

As larvas de T. molitor foram imobilizadas no gelo sendo em seguida dissecadas em solução de $\mathrm{NaCl} 342 \mathrm{mM}$. O tubo digestivo foi removido e o intestino médio isolado separando-se o epitélio ventricular $(\mathrm{EV})$ do conteúdo luminal delimitado pela membrana peritrófica (MP). Para os estudos de distribuição das atividades enzimáticas, os intestinos médios foram divididos em porção anterior (EVA; MPA), média (EVM; MPM) e posterior (EVP; MPP). Este material era, então, congelado a $20^{\circ} \mathrm{C}$ até o uso. As amostras eram descongeladas e homogeneizadas em água bidestilada, com o auxílio de um homogeneizador do tipo Potter-Elvehjem. Em seguida, EVA, EVM e EVP foram centrifugados a 20.000 g por 30 minutos a $4^{\circ} \mathrm{C}$ obtendo-se assim sobrenadante de EVA (SEVA), sobrenadante de EVM (SEVM), sobrenadante de EVP (SEVP), sedimento de EVA (PEVA), sedimento de EVM (PEVM), sedimento de EVP (PEVP). O conteúdo luminal do intestino médio foi separado em MPA, MPM e MPP. Estas amostras foram utilizadas em ensaios de distribuição da atividade ao longo do tubo digestivo deste inseto.

Para o isolamento das enzimas por cromatografia, o tubo digestivo das larvas de T. molitor era retirado o intestino médio separado e dividido em conteúdo luminal e epitélio, sendo que a membrana peritrófica e o conteúdo luminal foram utilizados como fonte de atividade enzimática. A membrana peritrófica e seu conteúdo foram homogeneizados em água bidestilada gelada com o auxílio de um homogeneizador do tipo Potter-Elvehjem. Em seguida, este material foi centrifugado a $20.000 \mathrm{~g}$ por 30 
minutos a $4^{\circ} \mathrm{C}$, o sedimento foi descartado e o sobrenadante recolhido. Esse material era, então, congelado à $20^{\circ} \mathrm{C}$ até o uso e usado como fonte de enzimas para purificação da dipeptidase e carboxipeptidase.

\section{3 - DETERMINAÇão DE PROTEÍNA}

A determinação da quantidade de proteína na amostra foi realizada utilizando o método descrito por Smith et al. (1985) e modificado por Morton e Evans (1992), usando-se uma curva padrão de albumina sérica bovina.

\section{4 - DETERMINAÇÃO DAS ATIVIDADES ENZIMÁTICAS}

Nos ensaios para detecção de todas as atividades enzimáticas a mistura de reação foi incubada em banho-maria termostatizado $\left(30^{\circ} \mathrm{C}\right)$ por quatro diferentes períodos de tempo. Foram utilizados brancos de enzima e brancos de substrato como controle. A atividade de aminopeptidase foi determinada utilizando-se como substrato LpNA 1 mM em tampão Tris-HCl 0,1 M pH 7,8 (Erlanger, 1961). O substrato utilizado na determinação de atividade de carboxipeptidase foi ZGly-Phe $20 \mathrm{mM}$ em tampão Tris $\mathrm{HCl}$ 0,1 M pH 8,0. A atividade de dipeptidase foi determinada utilizando-se Gly-Leu $20 \mathrm{mM}$ em tampão Tris- $\mathrm{HCl}$ 0,1 $\mathrm{M} \mathrm{pH} \mathrm{7,8} \mathrm{como} \mathrm{substrato.} \mathrm{A} \mathrm{atividade} \mathrm{de}$ carboxipeptidase e dipeptidase foi verificada através da medida da liberação de fenilalanina e leucina segundo Nicholson e Kim (1975). 
Todos os ensaios foram realizados nas condições em que a atividade era proporcional à concentração de proteína e ao tempo. $1 \mathrm{U}$ de enzima é definida como a quantidade de enzima que hidrolisa $1 \mu \mathrm{mol}$ de substrato (ou ligação) por minuto.

\section{5 - CROMATOGRAFIAS}

\subsection{1 - CROMATOGRAFIA PARA DESSAlinizAÇÃO DE AMOSTRA EM COLUNA}

\section{Hitrap Desalting}

Foi usada a coluna HiTrap Desalting, Amersham Biosciences. Esta cromatografia foi realizada manualmente, com utilização de seringa, a temperatura ambiente. A coluna foi previamente equilibrada com 5 volumes de coluna com tampão Tris-HCl 20 $\mathrm{mM}$ pH8,4 ou tampão piperazina $20 \mathrm{mM} \mathrm{pH} \mathrm{9,5.} \mathrm{1,5} \mathrm{mL}$ de amostra foram aplicados e a eluição foi feita com 2,0 mL de tampão.

As amostras foram ensaiadas, antes e após a dessalinização, com os substratos: LpNA, Gly-Leu, e ZGly-Phe para a determinação de atividade das enzimas aminopeptidase, dipeptidase e carboxipeptidase, respectivamente.

\subsection{2 - CROMATOGRAFIA DE TROCA IÔNICA}

Foi usada a coluna HiTrap Q XL (Amersham Biosciences) de 5,0 mL. A coluna foi acoplada ao sistema AKTA (Amersham Pharmacia Biotech), sendo a cromatografia realizada a temperatura ambiente. A eluição de proteína foi monitorada 
pela leitura a $280 \mathrm{~nm}$ e as frações obtidas foram analisadas quanto a sua atividade sobre os substratos LpNA, Gly-Leu e ZGly-Phe.O fluxo utilizado foi de 5,0 mL/min e as frações coletadas de $0,5 \mathrm{~mL}$. A coluna foi previamente equilibrada com 5 volumes de coluna com tampão piperazina $20 \mathrm{mM} \mathrm{pH} \mathrm{9,5.} \mathrm{A} \mathrm{amostra} \mathrm{foi} \mathrm{eluída} \mathrm{com} \mathrm{um}$ gradiente de $\mathrm{NaCl}$ de 0,2 a $0,6 \mathrm{M}$, no mesmo tampão.

As frações ativas após a eluição da coluna HiTrap Q foram aplicadas em uma coluna Resource Q (1,0 mL), (Pharmacia Biotech). A coluna foi acoplada ao sistema AKTA (Amersham Pharmacia Biotech), sendo a cromatografia realizada a temperatura ambiente. A eluição de proteína foi monitorada pela leitura a $280 \mathrm{~nm}$ e as frações obtidas foram analisadas quanto a sua atividade sobre os substratos LpNA, Gly-Leu e ZGly-Phe. O fluxo utilizado foi de $1,0 \mathrm{~mL} / \mathrm{min}$ e as frações coletadas de $0,4 \mathrm{~mL}$. A coluna foi previamente equilibrada com 5 volumes de coluna de tampão piperazina 20 $\mathrm{mM}$ pH 9,5. A amostra foi eluída com um gradiente de $\mathrm{NaCl}$ de 0,25 a 0,50 M na primeira Resource Q (1,0 mL), (Pharmacia Biotech) e com um gradiente de $\mathrm{NaCl}$ de 0,25 a 0,35 $\mathrm{M}$ na segunda Resource $\mathrm{Q}(1,0 \mathrm{~mL})$, (Pharmacia Biotech), ambos gradientes no mesmo tampão piperazina $20 \mathrm{mM} \mathrm{pH} \mathrm{9,5.}$

\subsection{3 - CROMATOGRAFIA DE GEL FILTRAÇÃO}

Foi usada a coluna Superdex 75 HR 10/30 (Pharmacia). A coluna foi acoplada ao sistema AKTA (Amersham Pharmacia Biotech), sendo a cromatografia realizada a temperatura ambiente. A eluição de proteína foi monitorada pela leitura a $280 \mathrm{~nm}$ e as 
frações obtidas foram analisadas quanto a sua atividade sobre os substratos, Gly-Leu e ZGly-Phe.O fluxo utilizado foi de $1 \mathrm{~mL} / \mathrm{min}$ e as frações coletadas de $0,4 \mathrm{~mL}$. A coluna foi previamente equilibrada com 2 volumes de coluna com tampão piperazina $20 \mathrm{mM} \mathrm{pH} \mathrm{9,5.}$

\section{6 - Eletroforese EM GEL DE POLIACRILAMIDA EM CONDIÇÕeS DESNATURANTES}

As amostras a serem submetidas à eletroforese tiveram o sal retirado através de diálise e, posteriormente, aquecidas durante 5 minutos a $95^{\circ} \mathrm{C}$ em tampão de amostra (Tris- $\mathrm{HCl} 60 \mathrm{mM}$, pH 6,8, contendo SDS 2\% (p/v), glicerol 10\%, $\beta$-mercaptoetanol 0,36 mM e azul de bromofenol 0,0025\%) e em seguida submetidas a uma separação eletroforética utilizando um equipamento Mini-Protean II (Bio-Rad, EUA) em gel de poliacrilamida $12 \%$ com 1,0 $\mathrm{mm}$ de espessura (Laemmli, 1970). As eletroforeses foram realizadas a $200 \mathrm{~V}$ e temperatura ambiente, até que o azul de bromofenol (utilizado como indicador da mobilidade eletroforética) estivesse a $0,5 \mathrm{~cm}$ da borda inferior da placa. O gel foi corado para visualização de proteínas com prata (Blum et al., 1987). O marcador de massa molecular utilizado foi o Low Range Prestained SDSPAGE Standards (Bio-Rad) contendo as seguintes proteínas: lisozima (14,4 kDa), inibidor de tripsina de soja (21,5 kDa), anidrase carbônica (31 kDa), ovalbumina (45 $\mathrm{kDa})$, albumina sérica bovina $(66,2 \mathrm{kDa})$, e fosforilase $\mathrm{B}(97,4 \mathrm{kDa})$. 


\section{7 - DiÁLISE}

A diálise foi feita para eliminar o sal presente nas amostras antes de submetê-las a eletroforese. Essa foi feita contra 100 volumes de água milli-Q ${ }^{\circledR}$, sendo realizadas três trocas. A membrana utilizada tinha o limite de exclusão de 12.000 Da.

\section{8 - DETERMINAÇÃO DO EFEITO DO PH SOBRE A ATIVIDADE DAS DIPEPTIDASE E}

\section{CARBOXIPEPTIDASE}

Essa determinação foi realizada usando preparações purificadas de dipeptidase e preparações do homogeneizado do conteúdo luminal de intestino médio das larvas de T. molitor para carboxipeptidase. Foi utilizada uma série de tampões: tampão Mes 0,2 M (pH 5,0; 6,0 e 7,0), tampão Tris-HCl 0,2 M (pH 7,0; 7,2; 7,4; 7,6; 7,8; 8,0; 8,5 e 9,0) e tampão piperazina $0,2 \mathrm{M}(\mathrm{pH} 10,0)$. Gly-Leu $40 \mathrm{mM}$ feito em água milli-Q ${ }^{\circledR}$ foi utilizado como substrato para dipeptidase e ZGly-Phe $4 \mathrm{mM}$ feito em água milli-Q ${ }^{\circledR}$ foi utilizado como substrato para carboxipeptidase. Tanto os ensaios quanto a determinação de $\mathrm{pH}$ das misturas de substrato e tampão foram realizadas a $30^{\circ} \mathrm{C}$. 


\section{9 - DETERMINAÇÃO DO $K_{M}$ E DA $V_{\text {MAX }}$ DA DIPEPTIDASE}

Esses experimentos foram realizados usando preparações purificadas de dipeptidase de Tenebrio molitor. Os substratos utilizados foram: Gly-Leu (1,0 a 35,0 mM), Gly-Phe (1,0 a 30,0 mM) e Leu-Gly (0,1 a 5,0 mM). O efeito da concentração de substrato sobre a atividade de dipeptidase foi determinado em tampão Tris- $\mathrm{HCl} 0,1 \mathrm{M}$ pH 7,8 a $30{ }^{\circ} \mathrm{C}$ usando doze concentrações diferentes de substrato. As velocidades de hidrólise do substrato foram determinadas e os dados obtidos aplicados ao programa Enzifitter (Elsevier Biosoft) para obtenção dos valores da constante de MchaelisMenten e da velocidade máxima.

\subsection{0 - ENSAIO DE INIBIÇÃO ENZIMÁTICA}

Os ensaios de inibição enzimática foram feitos determinando-se a velocidade de hidrólise de 9 concentrações de substrato na presença de 4 concentrações de inibidor. O inibidor utilizado foi o 1,10-fenantrolina. O Ki foi calculado a partir das inclinações dos plotes de Lineweaver-Burk versus concentração de inibidor (Segel, 1993) utilizando o programa Microsoft Excel. 


\section{4 - RESUlTADOS}

\section{1 - DistribuiÇÃO DA ATIVIDAdE DE DIPEPTIDASE E CARBOXIPEPTIDASE NAS DIFERENTES REGIÕES DO INTESTINO MÉDIO DE T. MOLITOR}

Com o intuito de se verificar o papel fisiológico das principais enzimas envolvidas na digestão final de peptídeos, o epitélio ventricular e a membrana peritrófica e o seu conteúdo foram divididos em três porções, nas quais foram determinadas as atividades de dipeptidase e carboxipeptidase (Tabela 1). Os resultados mostram que a dipeptidase encontra-se ao longo de todo ventrículo, principalmente, como uma enzima solúvel no conteúdo ventricular ( $88 \%$ da atividade total) e 13\% da atividade total encontram-se no EV. Carboxipeptidase ocorre também como uma enzima solúvel, sendo encontrada principalmente na porção média e posterior do conteúdo da MP (87\% da atividade total) e 5\% da atividade total sendo encontrada no EV.

\section{2 - PURIFICAÇÃo DA DIPEPTIDASE E DA CARbOXIPEPTIDASE PRESENTES NO CONTEÚDO LUMINAL DO INTESTINO MÉDIO DAS LARVAS DE T. MOLITOR}

A purificação da dipeptidase da carboxipeptidase a partir de homogeneizados do tubo digestivo deste inseto foi realizada com a utilização de cromaografias de troca iônica e de gel filtração. Como primeiro passo após a homogeneização e centrifugação 
(Materiais e Métodos) foi realizada uma cromatografia de troca catiônica em sistema de alta pressão (AKTA - Amersham Pharmacia Biotech), utilizando uma coluna HiTrap Q XL (5,0 mL), Amersham Biosciences. O perfil de atividade após está cromatografia é apresentado na figura 2. A recuperação de atividade neste procedimento é de $77 \%$ para dipeptidase e de $67 \%$ para carboxipeptidase. O enriquecimento é de 6 vezes para dipeptidase e de 5 vezes para carboxipeptidase em relação a preparação inicial. O eluído ativo é reunido e submetido a outra cromatografia de troca catiônica em sistema de alta pressão (AKTA - Amersham Pharmacia Biotech), utilizando uma coluna Resource Q (1,0 mL), Pharmacia Biotech. O perfil de atividade eluída desta cromatografia está representado na figura 3 , que mostra a resolução da aminopeptidase da mistura de carboxipeptidase e dipeptidase. A recuperação neste procedimento é de $9 \%$ para dipeptidase e de $16 \%$ para carboxipeptidase e há um enriquecimento de 9 e 16 vezes, respectivamente. O eluído ativo é reunido e submetido a outra cromatografia de troca catiônica em sistema de alta pressão (AKTA - Amersham Pharmacia Biotech), utilizando uma coluna Resource Q (1,0 mL), Pharmacia Biotech. O perfil de atividade eluída desta cromatografia está representado na figura 4, que mostra que a dipeptidase e aminopeptidase continuam juntas, apesar da remoção de muitas outras proteínas. A recuperação nete procedimento é de 3\% para dipeptidase e carboxipeptidase e há um enriquecimento de 13 e 12 vezes, respectivamente. O eluído ativo deste passo é reunido e submetido a uma cromatografia de gel filtração em sistema de alta pressão (AKTA - Amersham Pharmacia Biotech), utilizando uma coluna Superdex 75 HR 10/30, Pharmacia. O 
perfil de atividade eluída desta cromatografia está representado na figura 5, que mostra a resolução da carboxipeptidase e da dipeptidase. A recuperação neste procedimento é de $0,4 \%$ para dipeptidase e de $0,3 \%$ para carboxipeptidase e há um enriquecimento de 21 e 5 vezes, respectivamente. As recuperações e enriquecimentos desta marcha de purificação estão listados na tabela 2. As frações 16 a 24 da Superdex 75 (figura 5) foram dialisadas, secas por centrifugação a vácuo e submetidas a eletroforese em condições desnaturantes, para verificar o quão puras estavam a dipeptidase e a carboxipeptidase. $\mathrm{O}$ gel demonstra que essas enzimas estavam parcialmente purificadas (figura 6). Com o intuito de verificar quais eram as bandas de dipeptidase e carboxipeptidase, fizemos uma relação dos picos de atividades mostrados na Superdex 75 com intensidade das bandas mostradas no gel. Desse modo, a fração 19 que contém maior atividade sobre Gly-Leu, deveria corresponder à banda de maior intensidade na raia correspondente do gel, que interpretamos como sendo a banda de dipeptidase. Essa banda está marcada com um círculo vermelho na figura 5 do gel e o mesmo foi feito para localizar a banda de carboxipeptidase. Nesse caso é a fração 22 que contém a maior atividade sobre ZGly-Phe. A banda de maior intensidade na raia correspondente foi interpretada como sendo a banda de carboxipeptidase. $\mathrm{O}$ resultado confirma a resolução da dipeptidase e da carboxipeptidase, além de indicar a ocorrência de apenas uma dipeptidase e uma carboxipeptidase, com massas moleculares, respectivamente de $38,6 \mathrm{kDa}$ e $31,6 \mathrm{kDa}$. 


\section{3 - EFEITO DO PH SOBRE A ATIVIDADE DA DIPEPTIDASE E CARBOXIPEPTIDASE}

Ensaios enzimáticos para a verificação do efeito do $\mathrm{pH}$ sobre a atividade de dipeptidase e carboxipeptidase de $T$. molitor foram realizados, utilizando a dipeptidase purificada a partir dos tubos digestivos (frações 1819 da eluição descrita na Figura 5) a carboxipeptidase presente no conteúdo luminal deste inseto. As atividades recuperadas de carboxipeptidase no final da purificação descrita (frações 22 e 23, Figura 5) eram insuficientes e instáveis para continuar o estudo.

Estes resultados possibilitaram a obtenção de uma curva de atividade em função do $\mathrm{pH}$ e a determinação do $\mathrm{pH}$ ótimo dessas enzimas. $\mathrm{O}$ pH ótimo observado para dipeptidase de $T$. molitor foi de 7,6 (figura 7). A carboxipeptidase de T. molitor possui atividade em larga faixa de $\mathrm{pH}$ entre 6,5 e 7,7 com $\mathrm{pH}$ ótimo igual a 7,4 (figura 7).

\section{4 - PROPRIEDADES CINÉTICAS DA DIPEPTIDASE PURIFICADA}

A dipeptidase digestiva, purificada a partir de larvas $T$. molitor teve a sua atividade testada sobre os substratos Gly-Leu, Gly-Phe, Leu-Gly, Leu-Leu e Phe-Phe para determinação dos parametros cinéticos (tabela 3). Os resultados obtidos mostram uma clara preferência da dipeptidase, determinada pela razão $\mathrm{V}_{\max } / \mathrm{K}_{\mathrm{m}}$, por substratos com aminoácidos volumosos em P1 e P1'. A 1,10 fenantrolina é um inibidor não competitivo da dipeptidase digestiva de T. molitor (Ki igual a $062 \mathrm{mM}$ ) (Figura8). 


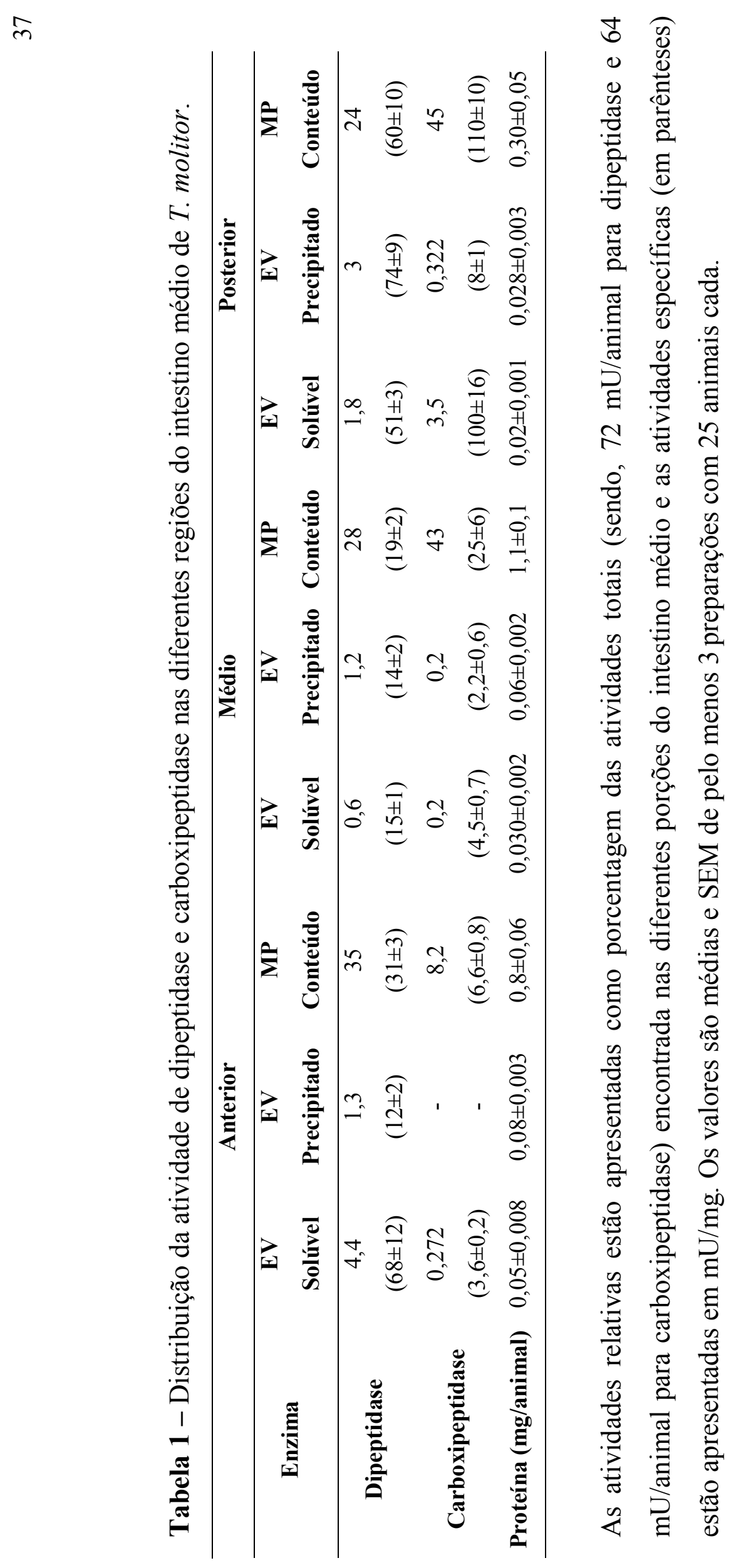




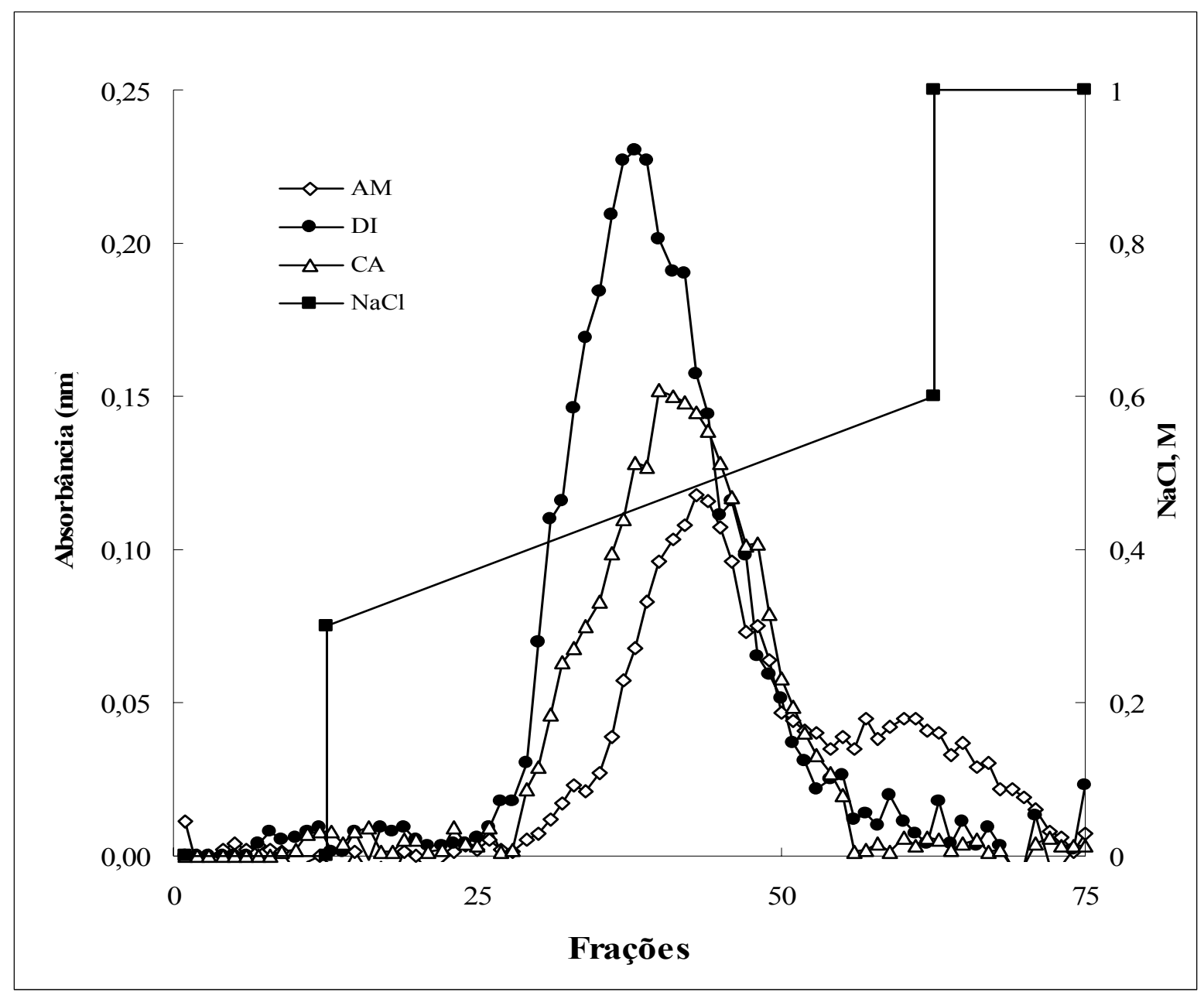

Figura 2 - Perfil cromatográfico para aminopeptidase, dipeptidase e carboxipeptidase. A fração solúvel do homogeneizado do conteúdo luminal do intestino médio de Tenebrio molitor foi aplicada em coluna em Hitrap Q e eluída com o gradiente de $\mathrm{NaCl}$ entre 0,2 e 0,6 M em tampão piperazina $20 \mathrm{mM}$ pH 9,5. A atividade enzimática foi determinada para os substratos LpNA, Gly-Leu e ZGly-Phe. A atividade para aminopeptidase foi detectada em $410 \mathrm{~nm}$ e as atividades para dipeptidase e carboxipeptidase foram detectadas em $420 \mathrm{~nm}$. AM, aminopeptidase; DI, dipeptidase; CA, carboxipeptidase. 


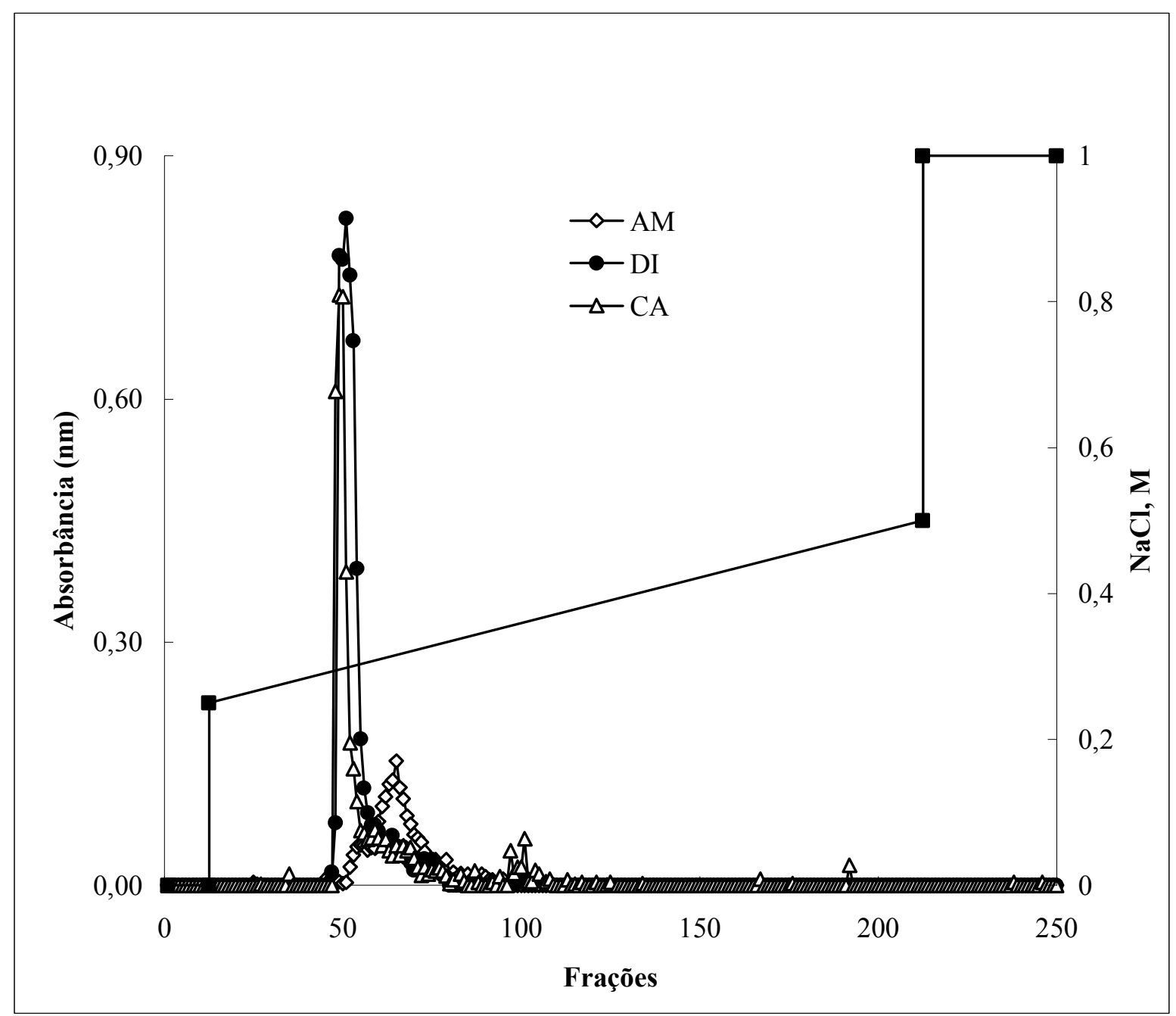

Figura 3 - Perfil cromatográfico para aminopeptidase, dipeptidase e carboxipeptidase. O Pool de atividade, formado pela reunião das frações 30 até 51 da cromatografia HiTrap Q, mostrada na figura 1, foi cromatografado em Resource Q com o gradiente de $\mathrm{NaCl}$ entre 0,25 e $0,5 \mathrm{M}$ em tampão piperazina $20 \mathrm{mM} \mathrm{pH}$ 9,5. A atividade enzimática foi determinada para os substratos LpNA, Gly-Leu e ZGly-Phe. A atividade para aminopeptidase foi detectada em $410 \mathrm{~nm}$ e as atividades para dipeptidase e carboxipeptidase foram detectadas em $420 \mathrm{~nm}$. AM, aminopeptidase; DI, dipeptidase; CA, carboxipeptidase. 


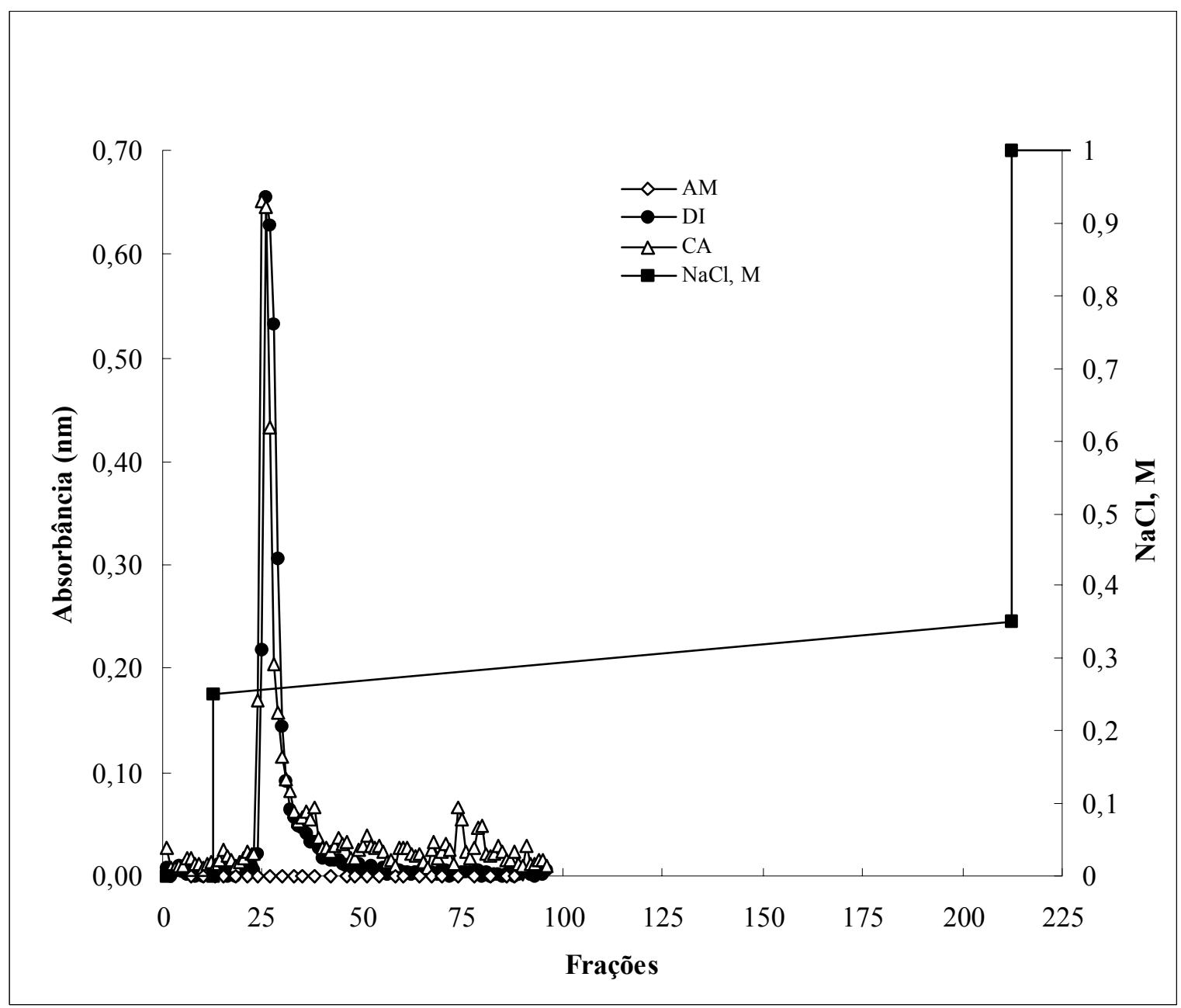

Figura 4 - Perfil cromatográfico para dipeptidase e carboxipeptidase. O Pool de atividade, formado pela reunião das frações 48 até 54 da cromatografia Resource Q, mostrada na figura 2, foi recromatografado em Resource Q com o gradiente de $\mathrm{NaCl}$ entre 0,25 e $0,35 \mathrm{M}$ em tampão piperazina $20 \mathrm{mM} \mathrm{pH} \mathrm{9,5.} \mathrm{A} \mathrm{atividade} \mathrm{enzimática} \mathrm{foi}$ determinada para os substratos, Gly-Leu e ZGly-Phe. As atividades para dipeptidase e carboxipeptidase foram detectadas em $420 \mathrm{~nm}$. AM, aminopeptidase; DI, dipeptidase; CA, carboxipeptidase. 


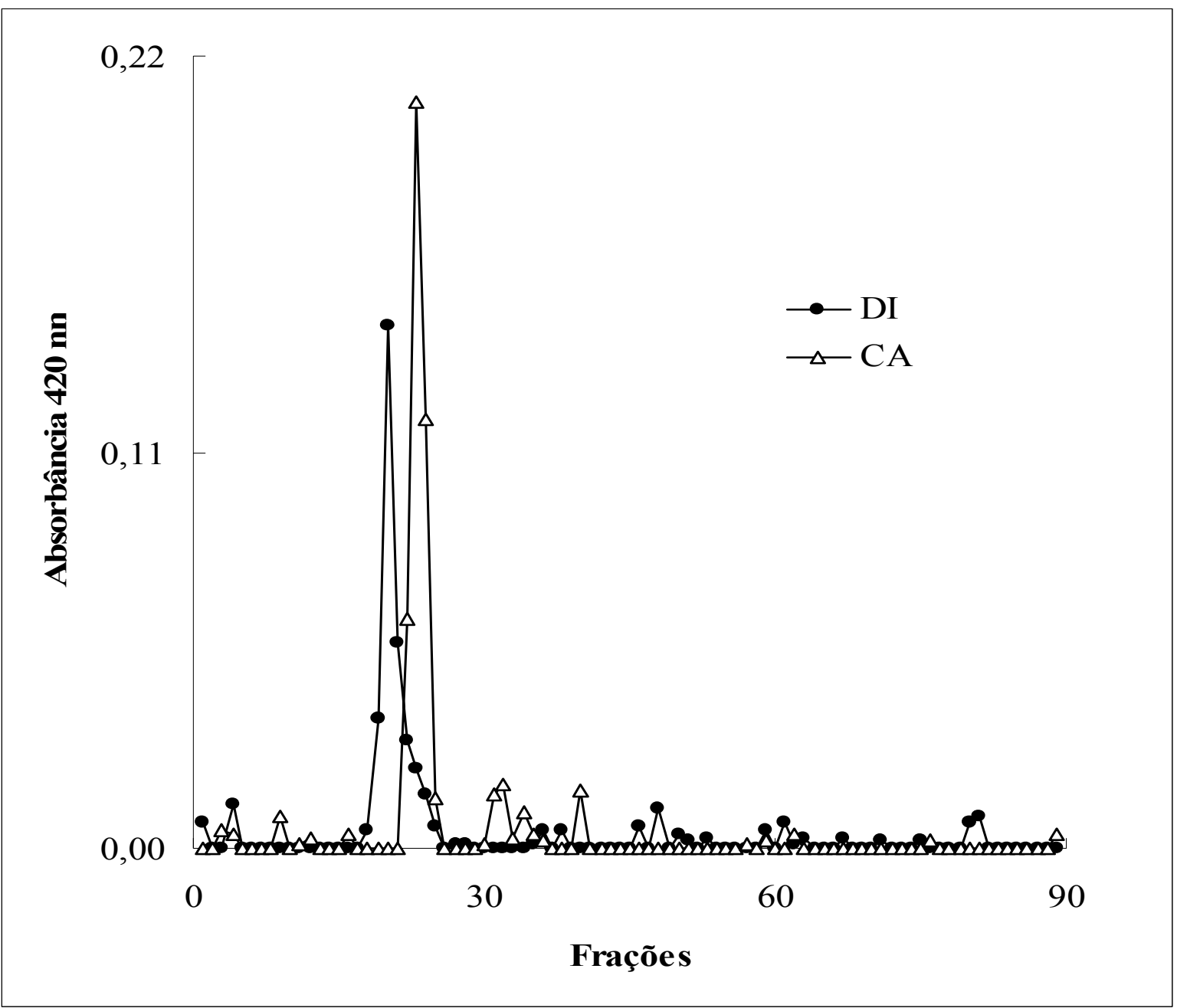

Figura 5 - Perfil cromatográfico para dipeptidase e carboxipeptidase. O Pool de atividade, formado pela reunião das frações 25 até 28 da cromatografia Resource Q, mostrada na figura 3, foi cromatografado em Superdex 75 em tampão piperazina 20 $\mathrm{mM} \mathrm{pH} \mathrm{9,5.} \mathrm{A} \mathrm{atividade} \mathrm{enzimática} \mathrm{foi} \mathrm{determinada} \mathrm{para} \mathrm{os} \mathrm{substratos,} \mathrm{Gly-Leu} \mathrm{e}$ ZGly-Phe. As atividades para dipeptidase e carboxipeptidase foram detectadas em 420 nm. 


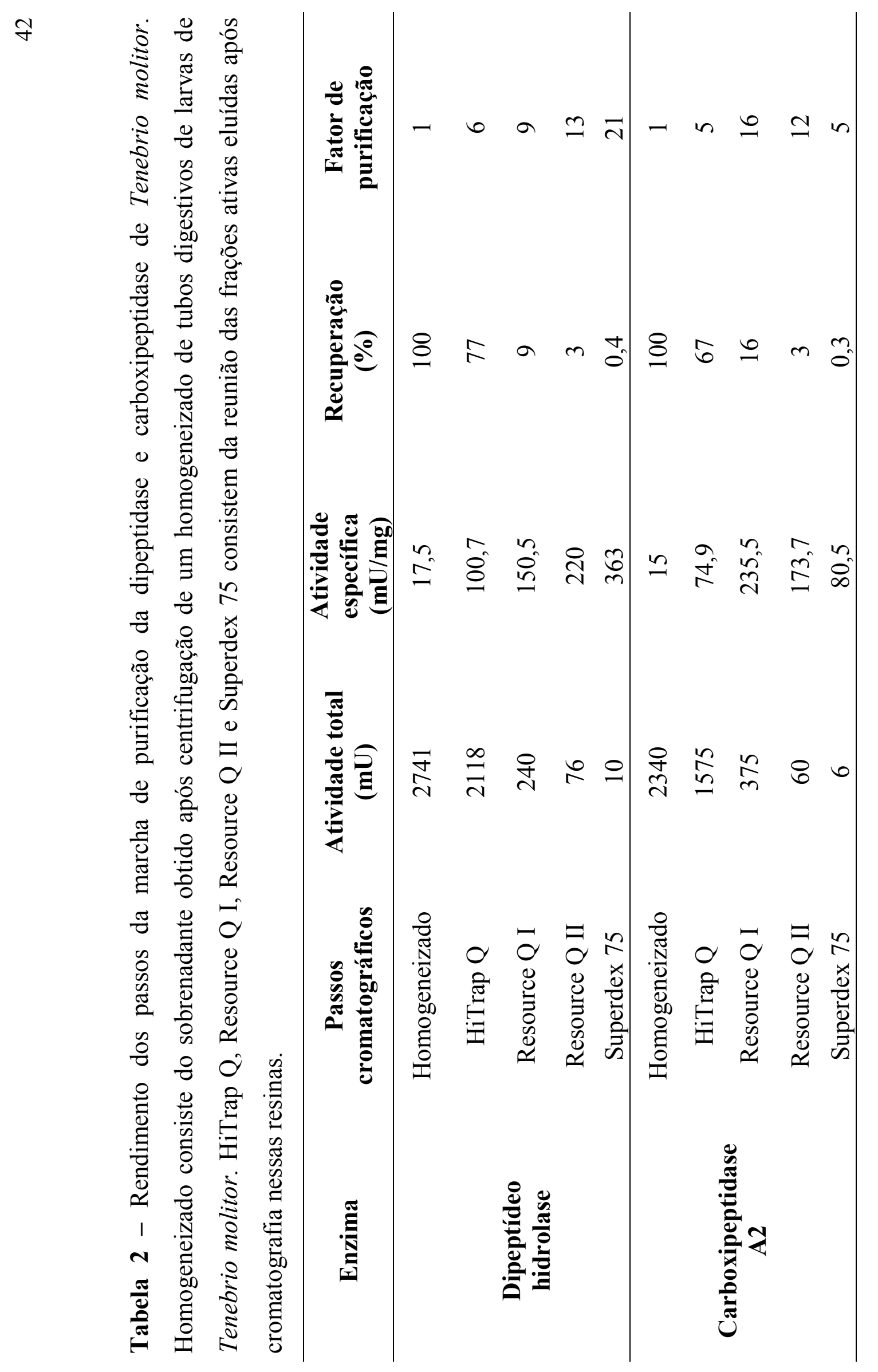




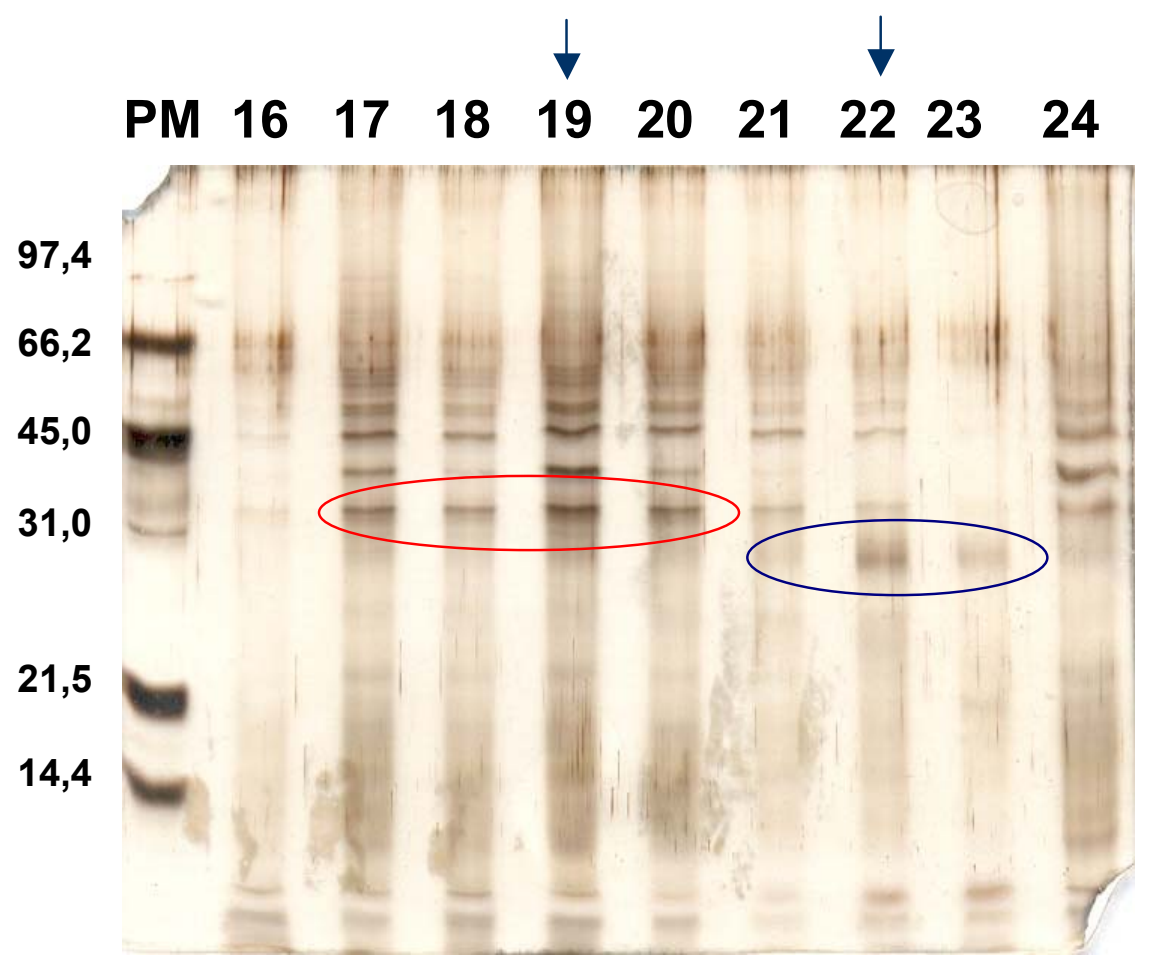

Figura 6 - SDS-PAGE em gel 12\% das frações 16 a 24 do eluido da coluna Superdex 75 (figura 4). As amostras aplicadas e PM foram submetidas a fervura antes de serem aplicadas no gel. Gel corado por prata segundo Blum et al. (1987) para evidenciar proteínas: PM - padrões de peso molecular. O círculo em vermelho indica a dipeptidase e o círculo em azul a carboxipeptidase. As setas correspondem aos picos da Figura 5. 

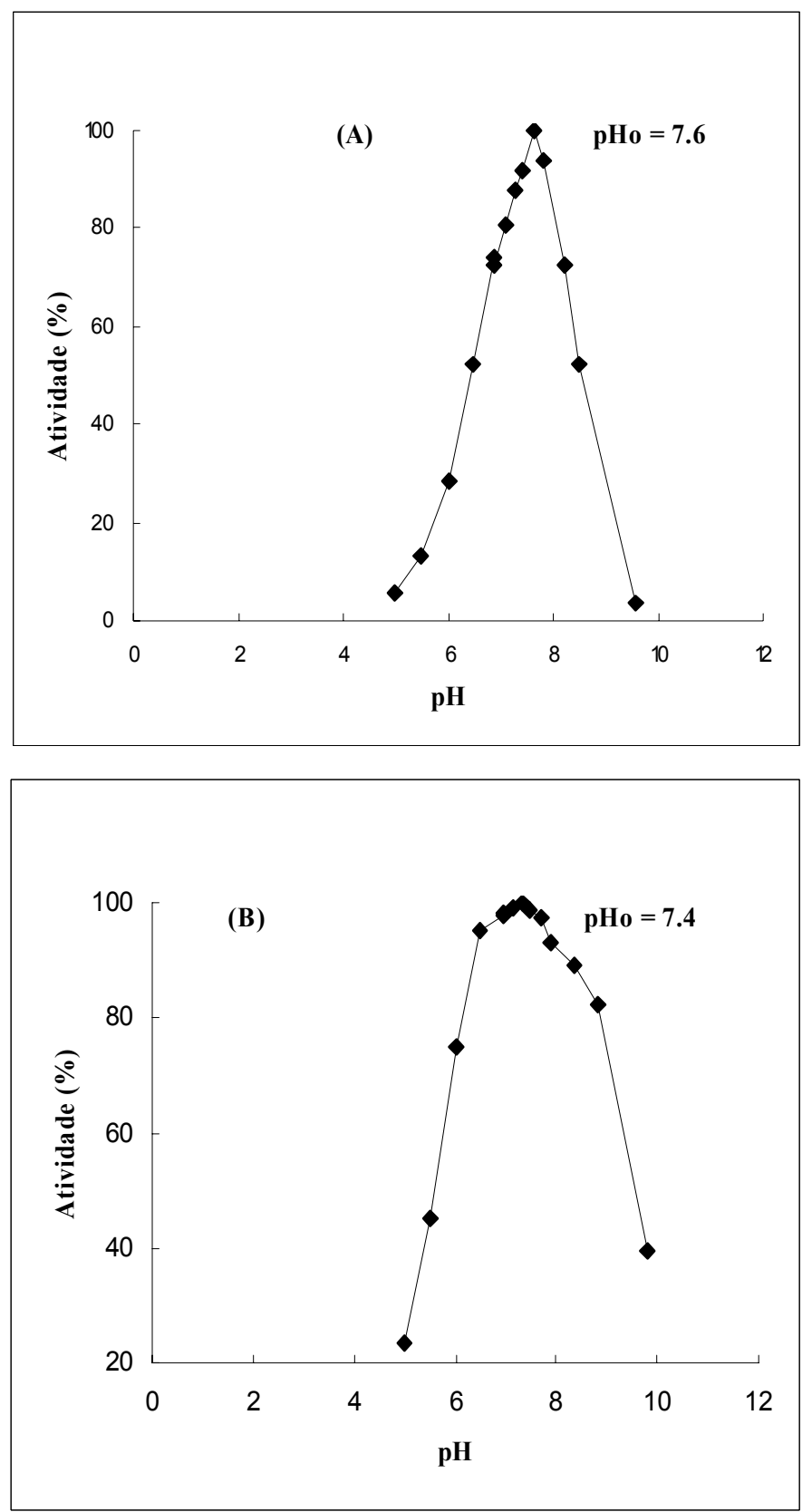

Figura 7 - Efeito do pH sobre a taxa de hidrólise de Gly-Leu (A) e ZGly-Phe (B). Foi utilizada uma série de tampões: tampão Mes 0,2 M (pH 5,0; 6,0 e 7,0), tampão Tris$\mathrm{HCl} 0,2 \mathrm{M}(\mathrm{pH} 7,0 ; 7,2 ; 7,4 ; 7,6 ; 7,8 ; 8,0 ; 8,5$ e 9,0) e tampão piperazina $0,2 \mathrm{M}(\mathrm{pH}$ 10,0). Tampões estavam em concentração de $0,1 \mathrm{M}$ e os substratos foram usados em uma concentração final de $20 \mathrm{mM}$ para Gly-Leu $0.2 \mathrm{mM}$ para ZGly-Phe. 
Tabela 3 - Determinação da eficiência catalítica da dipeptidase purificada de $T$. molitor, sobre cinco substratos diferentes.

\begin{tabular}{cccc}
\hline Substrato & $\begin{array}{c}\mathbf{V}_{\text {max }} \\
(\mathbf{m U} / \mathbf{m g})\end{array}$ & $\begin{array}{c}\mathbf{K}_{\mathbf{m}} \\
(\mathbf{m M})\end{array}$ & $\begin{array}{c}\mathbf{V}_{\mathbf{m a x}} / \mathbf{K}_{\mathbf{m}} \\
\left(\mathbf{m U} \cdot \mathbf{m g}^{-\mathbf{1}} \mathbf{m M}^{-\mathbf{1}}\right)\end{array}$ \\
\hline Gly-Leu & 244.4 & $9.7 \pm 0.7$ & 25 \\
Gly-Phe & 293.2 & $4.5 \pm 0.2$ & 65 \\
Leu-Gly & 574.4 & $1.0 \pm 0.1$ & 574 \\
Leu-Leu & 4607.7 & $0.31 \pm 0.04$ & 14863 \\
& & & 1005 \\
\hline
\end{tabular}

A fonte de enzima purificada corresponde as frações mais ativas da cromatografia descrita na Figura 5, após serem reunidas. 


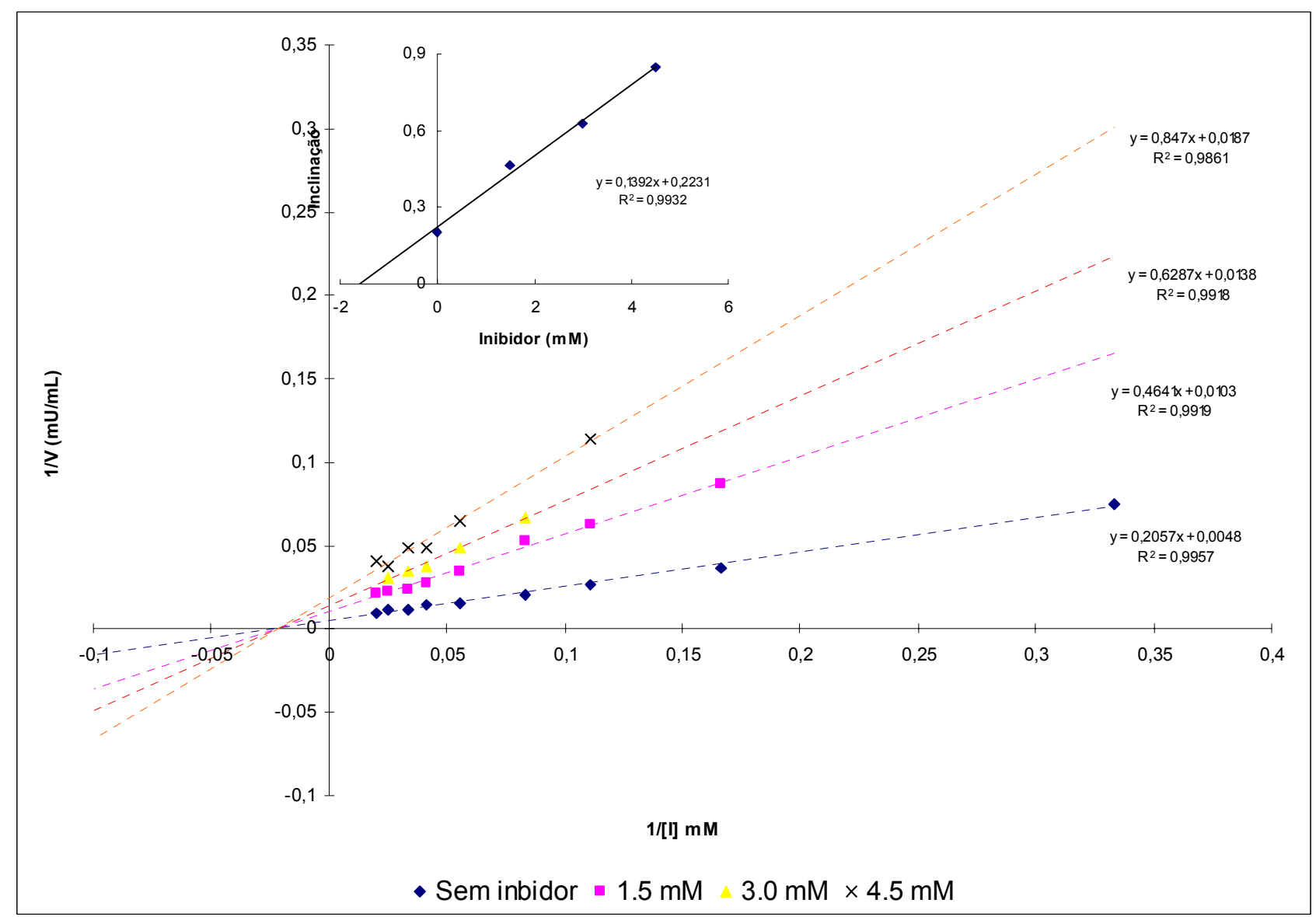

Figura 8 - Inibição por 1,10-fenantrolina da hidrólise de Gly-Leu pela dipeptidase purificada de intestino da larva de T. molitor. Os plotes de Lineweaver-Burk foram feitos para diferentes concentrações de substrato em cada concentração de inibidor (0 $\mathrm{mM} ; 1.5 \mathrm{mM} ; 3.0 \mathrm{mM}$ e $4.5 \mathrm{mM}$ ). Inserção: replote das inclinações calculadas dos plotes de Lineweaver-Burk versus a concentração de inibidor. 


\section{5 - DISCUSSÃO}

\section{1 - PURIFICAÇÃO DA DIPEPTIDASE E DA CARBOXIPEPTIDASE PRESENTES NO CONTEÚDO LUMINAL DO INTESTINO MÉDIO DAS LARVAS DE T. MOLITOR}

Com o objetivo de purificar a atividade majoritária da dipeptidase e carboxipeptidase presentes no conteúdo luminal do intestino médio das larvas de $T$. molitor (já que pelo resultado de distribuição, observamos que estas enzimas encontram-se majoritariamente no conteúdo), optamos começar por uma cromatografia de troca iônica, onde a coluna utilizada foi uma HiTrap Q e as proteínas foram eluídas em gradiente de $\mathrm{NaCl}$ de 0,2 a $0,6 \mathrm{M}$, utilizando o tampão piperazina 20 $\mathrm{mM} \mathrm{pH}$ 9,5. Uma preparação de homogeneizado de conteúdo luminal foi aplicada a esta coluna e as atividades de aminopeptidase, dipeptidase e carboxipeptidase foram medidas nas frações desta cromatografia (figura 2). A atividade de aminopeptidase foi medida para diferenciar sua atividade da atividade de dipeptidase, já que a aminopeptidase pode clivar substratos dipeptídicos como as dipeptidases (Cristofoletti e Terra, 1999). Observamos que as enzimas foram eluídas em concentrações de $\mathrm{NaCl}$ semelhantes. Em vista disso, mais três cromatografias de troca-iônica foram realizadas, seguida por uma filtração em gel, cujos dados estão resumidos na tabela 2.

Os resultados deixaram claro que há apenas uma dipeptidase e uma carboxipeptidase solúveis digestivas em $T$. molitor que foram resolvidas, embora cada preparação de enzima tivesse contaminada por outras proteínas. A carboxipeptidase 
era muito instável e pouco ativa, impedindo a realização de outros estudos. A dipeptidase apresentou uma massa molecular de 38,6 kDa e a carboxipeptidase apresentou uma massa molecular de 31,6 kDa determinados por SDS-PAGE. As carboxipeptidases de insetos possuem massas moleculares entre 20 e $50 \mathrm{kDa}$ (Terra e Ferreira, 1994) e Bown e colaboradores (1998) identificaram uma carboxipeptidase em Helicoverpa armigera com massa molecular de $35,5 \mathrm{kDa}$. Isso mostra que a banda mais enriquecida do gel pode ser minha proteína de interesse. Em mamíferos a massa molecular estimada por filtração em gel para dipeptidase varia entre 70 e $100 \mathrm{kDa}$ (Lenney, 1990; Priestman e Butterworth, 1985). Mayer e Nordwig (1973) relataram uma dipeptidase de $300 \mathrm{kDa}$, porém, indicaram que essa alta massa molecular poderia ser devido a formação de agregados. Uma massa molecular de $52,8 \mathrm{kDa}$ de uma dipeptidase de humano foi determinada por espectrometria de massa, enquanto que a massa molecular determinada por filtração em gel mostrou ser igual a 90 kDa, sugerindo que as dipeptidases formam homodímeros (Teufel et al., 2003), o que também foi observado em uma dipeptidase presente em no intestino delgado de macacos (Das e Radhakrishnan, 1973). Essa enzima apresentou uma massa molecular $107 \mathrm{kDa}$, através de estudos de filtração em gel, sendo composta de duas subunidades identicas de $52 \mathrm{kDa}$. 


\section{2 - PROPRIEDADES CINÉTICAS DA CARBOXIPEPTIDASE E DIPEPTIDASES} INTESTINAIS DE T. MOLITOR

O pH ótimo observado para dipeptidase de T. molitor foi de 7,6 (figura 7). A dipeptidase de diferentes organismos possuem $\mathrm{pH}$ ótimo bastante variado. Duas dipeptidases foram purificadas a partir do porco da Índia e denominadas dipeptidase I, que possui um $\mathrm{pH}$ ótimo igual a 9,0, e dipeptidase II, que possui um $\mathrm{pH}$ ótimo igual a 8,0 (Keane e O’Cuinn, 2002). Em humanos foi verificado uma dipeptidase com atividade ótima em $\mathrm{pH}$ alcalino, possuindo um $\mathrm{pH}$ ótimo igual a 9,5 (Teufel et al., 2003). Shao et al. (1997) purificou uma dipeptidase com atividade de prolinase, mas que também cliva dipeptídeos específicos para dipeptidases, presentes em Lactobacillus helveticus mostrou ter atividade ótima entre pH 6,0 e 6,5.

A carboxipeptidase de T. molitor possui atividade em larga faixa de $\mathrm{pH}$ entre 6,5 e 7,7 com pH ótimo igual a 7,4 (figura 7). Como já foi dito, enzimas digestivas similares a carboxipeptidase A são comuns em insetos e a maioria tem pH ótimo entre 7,5 e 9,0 (Terra e Ferreira, 1994). Bown e colaboradores, (1998) também observou uma carboxipeptidase presente no intestino médio de $H$. armigera com atividade ocorrendo em larga faixa de pH entre 7,5 e 10,0 e com atividade máxima observada em $\mathrm{pH}$ 8,0. Uma carboxipeptidase e uma carboxipeptidase B, presentes no homogeneizado de intestino médio de Trichoplusia ni mostraram atividades em pHs alcalinos, com faixa de $\mathrm{pH}$ ótimo igual a 8,0-8,5 para as duas enzimas (Wang et al., 2004). 
Como a dipeptidase não estava purificada não calculamos o valor de $\mathrm{K}_{\text {cat}}$, porém, foi calculado $\mathrm{V}_{\max } / \mathrm{K}_{\mathrm{m}}$. Esses resultados mostram que Leu-Gly é clivado com maior eficiência que Gly-Leu $\left(\mathrm{V}_{\max } / \mathrm{K}_{\mathrm{m}}\right.$ maior, ver Fersht, 1999), sugerindo que a dipeptidase de T. molitor prefere dipeptídeos com aminoácidos de cadeia lateral grande na posição P1. Por outro lado, a enzima prefere Leu-Leu a Leu-Gly, indicando que a ocorrência de grupo volumoso em P1 também é favorecida. Combinando os dados, correspondentes a $\mathrm{pH}$ ótimo, massa molecular, especificidade ampla para dipeptidase e baixa sensibilidade a fenantrolina,

discutida de T. molitor, dentre as dipeptidases melhor conhecida, assemelha-se mais à dipeptidase de membrana (Barret et al., 2004). Essa enzima (EC. 3.413.19) possui $\mathrm{pH}$ ótimo 7,5, maassa de $45 \mathrm{kDa}$ e Ki de cerca de $1 \mathrm{mM}$, embora possua ancora de glicosil-fosfatidil-inositol.

\section{3 - ORGANIZAÇão DA DIGESTÃo FINAL DE PROTEÍNAS}

Terra e Cristofoletti (1996) constataram a existência de uma cisteína proteinase na porção anterior e média do lúmen do tubo digestivo do T. molitor, enquanto que a tripsina e a quimotripsina localizam-se na região posterior deste, onde encontra-se também uma aminopeptidase microvilar (Cristofoletti e Terra, 1999). De acordo com essa distribuição, o pH luminal do ventrículo anterior e médio é ácido $(\mathrm{pH}=5,6)$ e do ventrículo posterior é alcalino $(\mathrm{pH}=7,9)($ Terra et al., 1985). Dessa forma a digestão 
inicial de proteínas começa sob a ação das cisteína proteinases e finaliza com tripsina e quimotripsina.

A presente dissertação confirma e detalha a existência de uma carboxipeptidase A, inicialmente descrita por Ferreira et al., (1990), presente majoritariamente nos dois terços finais do lúmen ventricular de T. molitor. Entretanto, levando em conta o pH luminal e o efeito do $\mathrm{pH}$ sobre a atividade de carboxipeptidase, cerca de $60 \%$ da atividade dessa enzima está no lúmen do ventrículo posterior e $25 \%$ no médio.

A dipeptidase descrita aqui é majoritariamente luminal, ocorre ao longo de todo o ventrículo com atividade levemente decrescente. Entretanto, corrigindo as atividades para aquelas esperadas pelo seu comportamento frente ao $\mathrm{pH}$, o ventrículo posterior concentra $67 \%$ da atividade de dipeptidase.

Desse modo, os peptídeos gerados pela hidrólise das endopeptidases luminais são atacados seqüencialmente, principalmente no ventrículo posterior, pela carboxipeptidases e aminopeptidase microvilar, finalmente, pelas dipeptidases solúveis. Os aminoácidos formados na digestão são carreados através de um contrafluxo para a região anterior do epitélio do ventrículo, onde supostamente ocorre a absorção (Terra e Ferreira, 1994). 


\section{6 - CONCLUSÕES}

- As atividades de dipeptidase e carboxipeptidase encontram-se majoritariamente no conteúdo luminal do intestino médio de larvas de T. molitor;

- A carboxipeptidase de T. molitor possui pH ótimo 7,4 e massa molecular de $31,6 \mathrm{kDa}$;

- A dipeptidase digestiva de T. molitor possui massa molecular de $38,6 \mathrm{kDa}, \mathrm{pH}$ ótimo 7,6, baixa solubilidade a fenantrolina e parece preferir dipeptídeos com cadeia lateral volumosa na posição P1 e em menor extensão também em P1';

- A digestão final de proteínas deve ocorrer majoritariamente no ventrículo posterior de larvas de T. molitor. 


\section{7 - BIBLIOGRAFIA}

Avilés, F.X., Vendrell, J., Guasch, A., Coll, M., Huber, R., 1993. Advances in metalloprocarboxypeptidases. Emerging details on the inhibition mechanism and on the activation process. Eur. J. Biochem. 211, $381-389$.

Barrett, A.J., Rawlings, N. D. e Woessner, J. F., (2004) (Eds). Handbook of Proteolytic Enzymes Academic Press, London.

Blum, H., Beier, H., Gross, H.J., 1987. Improved silver staining of plant proteins, RNA and DNA in polyacrylamide gels. Electrophoresis 8, 93-99.

Bobrowski, V.L., Fiuza, L.M., Pasquali, G., Bodanese-Zanettini, M.H., 2003. Genes de Bacillus thuringiensis: uma estratégia para conferir resistência a insetos em plantas. Ciência Rural, Santa Maria. 34, 843 - 850.

Bown, D.P., Gatehouse, J.A., 2004. Characterization of a digestive carboxypeptidase from insect pest corn earworm (Helicoverpa armigera) with novel specificity towards C-terminal glutamate residues. Eur. J. Biochem. 271, 2000 - 2011.

Bown, D.P., Wilkinson, H.S., Gatehouse, J.A., 1998. Midgut carboxypeptidase from Helicoverpa armigera (Lepdoptera: Noctuidae) larvae: enzyme characterization, cDNA cloning and expression. Insect Biochem. Mol. Biol. 28, 739 - 749.

Chapman R.F., 1985. Structure of the digestive system. In comprehensive insect physiology, Biochemistry and Pharmacology (Edited by Kerkut, G. A. e Gilbert, L. I.), vol. 4, pp. 165 - 211. Pergamon Press, New York. 
Chen, Yuan-Shou, Chien, Chia-Hui, Goparaju, C. M., Hsu, J. Tsu-Na, Liang, PoHuang, Chen, X., 2004. Purification and characterization of human prolyl dipeptidase DPP8 in Sf9 insect cells. Protein Expression and Purification 35, 142 $-146$.

Cristofoletti, P.T., Ribeiro, A.F., Terra, W.R., 2001. Apocrine secretion of amylase and exocytosis of trypsin along the midgut of Tenebrio molitor. J. Insect Physiol. $47,143-155$.

Cristofoletti, P.T., Ribeiro, A.F., Terra, W.T., 2005. The cathepsin L-like proteinasesfrom the midgut of Tenebrio molitor larvae: Sequence, properties, immunocytochemical localization and function. Insect Biochem. Mol. Biol. 35, $883-901$.

Cristofoletti, P.T., Terra, W.R., 1999. Specificity anchoring, and subsites in the active center of a microvillar aminopeptidase purified from Tenebrio molitor (Coleoptera) midgut cells. Insect Biochem. Mol. Biol. 29, 807-819.

Das, M. e Radhakrishnan, A. N. (1973). Glycyl-L-Leucine hydrolase, a versatile “master” dipeptidase from monkey small intestine. Biochem. J. 135, 609 - 615.

Edwards, M.J., Lemos, F.J. A., Donnelly-Doman, M., Jacobs-Lorena, M., 1997. Rapid induction by a blood meal of a carboxypeptidase gene in the gut of the mosquito Anopheles gambiae. Insect Biochem. Mol. Biol. 27, 1063-1072.

Edwards, M.J., Moskalyk, L.A., Donelly-Doman, M., Vlaskova, M., Noriega, F.G., Walker, V.K., Jacobs-Lorena, 2000. Characterization of a carboxypeptidase A gene from the mosquito, Aedes aegypti. Insect Mol. Biol. 9, 33 - 38 . 
Erlanger, B.F., Kokowsky, N., Cohen, W., 1961. The preparation and properties of two new chromogenic substrates of trypsin. Arch. Biochem. Biophys. 95, 271278.

Estébanez-Perpiñá, E., Bayes, A., Vendrell, J., Jongsma, M.A., Bown, D.P., Gatehouse, J., Huber, R., Bode, W., Avilés, F.X., Reverter, D., 2001. Crystal structure of a novel midgut procarboxypeptidase from the cotton pest Helicoverpa armigera. J. Mol. Biol. 313, 629-638.

Ferreira, C., Bellinello, G.L., Ribeiro, A.F., Terra, W.R., 1990. Digestive enzymes associated with the glycocalyx, microvillar membranes and secretory vesicles from midgut cells of Tenebrio molitor larvae. Insect Biochem. 20, $839-847$.

Ferreira, C., Capella, A.N., Sitnik, R., Terra, W.R., 1994. Properties of the digestive enzymes and the permeability of the peritrophic membrane of Spodoptera frugiperda (Lepidoptera) larvae. Comp. Biochem. Physiol. 107A, 631 - 640.

Ferreira, C., Terra, W.R., 1989. Spatial organization of digestion, secretory mechanisms and digestive enzyme properties in Pheropsophus aequinoctialis (Coleoptera: Carabidae) Insect Biochem. 19, 383-391.

Fersht, A., 1999. Structure and mechanism protein science: a guide to enzyme catalysis and protein folding. W. H. Fresman, New York.

Garcia, E.S., Guimarães, J.A., 1979. Proteolytic enzymes in the Rhodnius prolixus midgut. Experientia 35, 305-306.

Gardell, S.J., Craik, C.S., Clauser, E., Goldsmith, E.J., Stewart, C.B., Graf, M., Rutter, W.J., 1988. A novel rat carboxypeptidase, CPA2: characterization, molecular 
cloning, and evolutionary implications on substrate specificity in the carboxypeptidase gene family. J. Biol. Chem. 263, $17828-17836$.

Hall, N.A., 1988. Peptidases in Drosophila melanogaster II. The variation of peptidases activities during development. Insect Biochem. 18, 145-155.

Hilder, V.A., Boulter, D., 1999. Genetic engeneering of crop plants for insect resistance - a critical review. Crop Protection, Oxford. 18, 177 - 191.

Jordão, B.P., Terra, W.R., 1989. Distribution, properties, and functions of midgut carboxypeptidases and dipeptidases from Musca domestica larvae. Arch. Insect Biochem. Physiol. 11, 231-244.

Keane, F. e O’Cuinn, G., (2002). Two broad-specificity dipeptide hydrolysing activities from cytoplasm of guinea pig brain, both of which contain prolinase but neither of which contain carnosinase activity. Neur. Res. 44, 111 - 120.

Khan, M.A., 1962. The distribution of dipeptidase activity in the digestive system of Locusta migratoria and Dysdercus fasciatus. Comp. Biochem. Physiol. 6, 169170.

Klinkowstrom, A.M., Terra, W.R., Ferreira, C., 1995. Midgut dipeptidases from Rhynchosciara americana (Diptera) larvae. Properties of soluble and membrane bound forms. Insect Biochem. Mol. Biol. 25, 303-310.

Laemmli, U.K., 1970. Cleavage of structure proteins during the assembly of the head of bacteriophage T4. Nature 227, 680-685.

Lenney, J.F., 1990. Human cytosolic carnosinase. Evidence of identity with prolinase, a non-specific dipeptidase. Biol. Chem. Hoppe-Seyler. 371, 161 - 171. 
Levinsky, H., Birk, H., Appeblaum S.W., 1977. Isolation and characterization of a new trypsin-like enzyme from Tenebrio molitor larvae. Int. J. Pept. Res. 10, 252 - 264. Mayer, H., Nordwig, A., 1973. The cleavage of prolyl peptides by kidney peptidases. Purification of iminodipeptidase (prolinase). Hopper-Seyler's Z. Physiol. Chem. $354,371-379$.

McGaughey, W.H., Whalon, M.E., 1992. Managing insect resistence to Bacillus thuringiensis toxins. Science. 258, $1451-1455$.

Morton, R.E., Evans, T.A., 1992. Modification of the bicinchoninic acid protein assay to eliminate lipid interference in determining lipoprotein protein content. Analytical Biochemistry 204, 332-334.

Nicholson, J.A., Kim, Y.S., 1975. A one-step L-amino acid oxidase assay for intestinal peptide hydrolase activity. Analyt. Biochem. 63, 110-117.

Nomenclature Committee of the International Union of Biochemistry and Molecular Biology, 1992. Enzyme Nomenclature 1992. Academic Press, New York.

Priestman, D.A. e Butterworth, J., (1985). Prolinase and non-specific dipeptidases of human kidney. Biochem. J. 231, 689 - 694.

Ramos, A., Mahovald, A., Jacobs-Lorena, M., 1993. Gut-specific genes from the black-fly Simulium vitatum encoding trypsin-like and carboxypeptidase-like proteins. Insect Mol. Biol. 1, 149-163.

Richards, O.W., Davis, R.G., 1977. Imm's General textbook of entomology. 10 Ed., Chapman, London, 1354 pp. 
Segel, H.I. (1993) Enzymes kinetics. Behavior and analysis of rapid equilibrium and steady-state enzyme systems. Jonh Wiley \& Sons, New York.

Shao, W., Yuksel, G. U., Dudley, E. G., Parkin, K. L. e Steele, J. L., (1997). Biochemical and molecular characterization of PepR, a dipeptidase, from Lactobacillus helveticus CNRZ32. Appl. Env. Microbiol. 63, 3438 - 3443.

Smith, P.K., Krohn, R.I., Hermanson, G.T., Mallia, A.K., Gartner, F.H., Provenzano, M.D., Fujimoto, E.K., Goeke, N.M., Olson, B.J., Klenk, D.C., 1985. Measurement of protein using bicinchoninic acid. Analytical Biochemistry 150, $76-85$.

Terra W. R., Ferreira C., 2004. Biochemistry of digestion In: Gilbert, L. I. Latrov, K., Gill, S. (Eds.), Comprehensive Insect Physiology, Biocemistry, Pharmacology and Molecular Biology, Vol. 4, Biochemistry and Molecular Biology. Elsevier, Oxford, in press.

Terra W.R., Ferreira C., 2005. Biochemistry of digestion In: Gilbert, L. I. Iatrou, K., Gill, S. S. (Eds.), Comprehensive Insect Physiology, Biocemistry, Pharmacology and Molecular Biology, Vol. 4, Biochemistry and Molecular Biology. Elsevier, Oxford, in press.

Terra, W. R. e Ferreira C., 1994. Insect digestive enzymes: properties, compartmentalization and function. Comp. Biochem. Physiol. 109B, 1-62.

Terra, W.R., 1990. Evolution of digestive systems of insects. Annu. Rev. Entomol. 35, $181-200$. 
Terra, W.R., Espinoza-Fuentes, F.P., Ribeiro, A.F., Ferreira, C., 1988. The larval midgut of the housefly (Musca domestica): ultrastructure, fluid fluxes and ion secretion in relation to the organization of digestion. J. Ins. Physiol. 24, $463-$ 472.

Terra, W.R., Ferreira, C., Bastos, F., 1985. Phylogenetic considerations of insect digestion: disaccharidases and the spatial organization of digestion in the Tenebrio molitor larvae. Insect Biochem. 15, 443 - 449.

Terra, W.R.; Cristofoletti, P.T., 1996. Midgut proteinases in three divergent species of Coleoptera. Comp. Biochem. Physiol., 113B, 725-730.

Teufel, M., Saudek, V., Ledig, JP., Bernhardt, A., Boularand, S., Carreau, A., Cairns, N. J., Carter, C., Cowley, D. J., Duverger, D., Ganzhorn, A. J., Guenet, C.,

Vendrell, J., Querol, E., Avilés, F.X., 2000. Metallocarboxypeptidases and their protein inhibitors structure, function and biomedical properties. BBActa 1477 , $284-298$.

Wang, P., Li G., Kain, W., 2004. Characterization and cDNA cloning of midgut carboxypeptidase from Trichoplusia ni. Insect Biochem. Mol. Biol. 34, 831-843. 
8 - SÚMULA CURRICULAR

\section{DADOS PESSOAIS}

Nome: Érica Moreira de Oliveira

Local e data de nascimento: Itaperuna/RJ, 12 de Setembro de 1980.

\section{EDUCAÇÃo}

Universidade, local, ano.: Universidade Estadual do Norte Fluminense Darcy Ribeiro (UENF), Campos dos Goytacazes/RJ, 2004

Graduação (Modalidade) Graduação em Ciências Biológicas

Universidade, local, ano.: Universidade de São Paulo (USP), São Paulo/SP, 2008.

Mestrado em Bioquímica.

\section{OCUPAÇÃO}

Bolsista de Mestrado/Doutorado, Agência, vigência da bolsa: Bolsista de Mestrado, CNPq, 2004-2006

\section{PublichÇões (ARtigos Completos e Resumos em Congressos)}

\section{ARTIGOS:}

CAMPOS, E. ; MORAES, J. ; FACANHA, A. R. ; Moreira, E. ; VALLE, D. ; MASUDA, A. ; MANSO, P. P. A. ; NASCIMENTO, A. ; VAZ JR., I. ; LOGULLO, C. . Kinetics of energy source utilization in Boophilus microplus (Canestrini, 1887) (Acari: Ixodidae) embryonic development. Veterinary Parasitology, v. 138, p. 349357, 2006. 


\section{RESUMOS EM CONGRESSOS:}

Moreira, E. ; LOPES, A. R. ; TERRA, W. R. . Partial purification and characterization of a carboxypeptidase and a dipeptidase from Tenebrio molitor larvae. In: XXXV Reunião Anual da Sociedade Brasileira de Bioquímica e Biologia Molecular SBBq, 2006, Águas de Lindóia. XXXV Reunião Anual da Sociedade Brasileira de Bioquímica e Biologia Molecular SBBq, 2006.

Moreira, E. ; MASUDA, A. ; LOGUllO, C. ; VAZ JR., I. ; MORAES, J. . Lipid Composition and Utilization During Boophilus microplus Embryogenesis. In: XXXIII ${ }^{\mathrm{a}}$ Reunião Anual da Sociedade Brasileira de Bioquímica e Biologia Molecular - SBBq, 2004, Caxambu - MG. XXXIII Reunião Anual da Sociedade Brasileira de Bioquímica e Biologia Molecular - SBBq, 2004.

Moreira, E. ; MASUDA, A. ; LOGUllo, C. ; TERMIGNONI, C. ; VAZ JR., I. ; MORAES, J. . Lipid metabolism during Boophilus micoplus embryogenesis. In: XXXII Reunião Anual da Sociedade Brasileira de Bioquímica e Biologia Molecular SBBq, 2003, Caxambu - MG. XXXII Reunião Anual da Sociedade Brasileira de Bioquímica e Biologia Molecular - SBBq, 2003.

Moreira, E. ; MASUDA, A. ; LOGULlO, C. ; TERMIGNONI, C. ; VAZ JR., I. ; MORAES, J. . Metabolismo de lipídeo durante o desenvolvimento embrionánio do carrapato bovino Boophilus micoplus. In: $8^{\circ}$ Encontro de Iniciação Científica, realizado na UENF, 2003, Campos dos Goytacazes. $8^{\circ}$ Encontro de Iniciação Científica, realizado na UENF, 2003. 